\title{
A Transient Hot Wire Thermal Conductivity Apparatus for Fluids*
}

\author{
Hans M. Roder \\ National Bureau of Standards, Boulder, CO 80303
}

May 26, 1981

\begin{abstract}
A new apparatus for measuring the thermal conductivity of fluids is described. This is an absolute method utilizing a transient hot wire. Measurements are made with a $12.7 \mu \mathrm{m}$ diameter platinum wire at real times of up to 1 second. The data acquisition system includes a minicomputer and a digital voltmeter. The experimental core of the system incorporates a compensating hot wire in a Wheatstone bridge circuit. The cell containing the core of the apparatus is designed to accommodate pressures from 0 to $70 \mathrm{MPa}$ and temperatures from 70 to 320 K. Oxygen was measured over a wide range of physical states including the dilute gas, the moderately dense gas, the near critical region, the compressed liquid states, and the vapor at temperatures below the critical temperature. Performance checks of the apparatus were conducted with nitrogen, helium and argon. Measurement of rare gases allows a direct comparison to the kinetic theory of gases through the viscosity. A second check looks at the variation of the measured thermal conductivity as a function of the applied power. The precision $(2 \sigma)$ of the new system is between 0.5 and 0.8 percent for wire temperature transients of 4 to $5 \mathrm{~K}$, while the accuracy is estimated at around 1.5 percent.
\end{abstract}

Key words: Helium; hot wire; nitrogen; pressure; temperature; thermal conductivity; transient.

\section{Introduction}

Thermal conductivity values are necessary whenever a heat transfer problem is to be evaluated. In addition, thermal conductivity is a property of fundamental interest in developing the theory of fluids. Accurate measurements of thermal conductivity are of considerable difficulty. Methods and geometries abound each with its adherents and its inherent drawbacks. The steady state hot wire experiment is one of the older, well established methods. The transient hot wire method, however, has come into its own only with recent advances in digital electronics. The evolution of the modern transient hot wire experiment can be traced from the early experiments of Pittman [1] ${ }^{1}$, Haarman [2], and Mani [3]. However, the major exposition of both theory and application of this method was accomplished by Kestin and his coworkers during the last decade [4-9] for the gas phase. Similar instruments have been used by Wakeham and his coworkers for both gas and liquid measurements $[10,11]$ and by de Castro and his coworkers for liquid measurements [12-13].

\footnotetext{
"This work was carried out at the National Bureau of Standards under the sponsorship of the National Aeronautics and Space Administration (C-32369-C).

†Thermophysical Properties Division, National Engineering Laboratory.

${ }^{1}$ Figures in brackets indicate literature references at the end of this paper.
}

\section{Method}

A hot wire system normally involves a vertical, cylindrical symmetry where the wire serves both as heating element and as thermometer. Almost without exception platinum is the wire of choice. The mathematical model that one attempts to approximate is that of an infinite line source of heat suspended vertically in an infinite medium. The method is labeled transient because the power is applied abruptly and the measurement is of short duration. The working equation is based on a specific solution of Fourier's law and can be found in standard texts (see for example reference [14], page 261).

$$
T(t)-T_{\text {ref }}=\Delta T=\frac{q}{4 \pi \lambda} \ln \left(\frac{4 K}{a^{2} C} t\right)
$$

Where $T(t)$ is the temperature of the wire at time $t$;

$T_{\text {ref }}$ is the reference temperature, the temperature of the cell;

$q$ is the applied power;

$\lambda$ is the thermal conductivity of the fluid, a function of both temperature and density;

$K$ is the thermal diffusivity of the fluid, i.e., $K=$ $\lambda i \varrho C_{p} . K$ is normally taken at the temperature $T_{\text {ref }}$ and is nearly constant since the fluid properties do 
not change drastically with a small increase in temperature;

$a$ is the radius of the wire; and

ln $C=\gamma$ where $\gamma$ is Euler's constant.

The relation given by eq (1) implies a straight line for a plot of $\Delta T$ versus $\ln (t)$. In practice systematic deviations occur at both short and long times. However, for each experimental measurement there exists a range of times over which eq (1) is valid, that is the relation between $\Delta T$ and $\ln (t)$ is linear. This range of validity is determined from 250 measured $\Delta T \cdot t$ pairs by selecting a beginning time $t_{1}$ and an ending time $t_{\mathbf{2}}$. The slope of the $\Delta T$ versus $\ln (t)$ relation is obtained over the valid range, i.e., between times $t_{1}$ and $t_{2}$, and using the applied power the thermal conductivity is calculated from eq (1). The temperature assigned to the measurement of $\lambda$ is given by

$$
T=T_{\text {ref }}+\frac{1}{2}\left[\Delta T\left(t_{1}\right)+\Delta T\left(t_{2}\right)\right]
$$

The density assigned to the measurement of $\lambda$ is taken from an equation of state using an experimentally measured pressure and the temperature assigned above. The equations of state used for nitrogen and helium are given in subsequent sections. The experimentally determined term. perature rise of the wire is $\Delta T_{w}$. A number of corrections account for the departure of the real instrument from the ideal model:

$$
\Delta T=\Delta T_{w}-\Sigma \delta T_{i}
$$

These corrections $\delta T_{i}$ have been fully described elsewhere [5]; the most important at lower times is $\delta T_{1}$, the effect of the finite heat capacity of the wire.

\section{Apparatus}

The various elements of the apparatus, the hot wires, the high pressure cell and wire supports, the Wheatstone bridge, the cryostat, the measuring and control circuitry, the sample handling system, and the minicomputer are described here and in figures 1-6.

\subsection{The Hot Wires}

Platinum wire is the normal choice because the resistance-temperature relation of platinum is well known [15]. In the resistance thermometer grade of the wire the smallest sizes available commercially are $7 \mu \mathrm{m}, 12.7 \mu \mathrm{m}$, and $25.4 \mu \mathrm{m}$ in diameter. The smallest of these was considered to be too fragile for the present application, the largest would not provide a sufficiently large resistance for the cell size under consideration. Therefore, the $12.7 \mu \mathrm{m}$ diameter wire was chosen for both primary and compensating hot wire. The long or primary hot wire is approximately $10 \mathrm{~cm}$ in length. Its resistance varies from about $20 \Omega$ at $76 \mathrm{~K}$ to $90 \Omega$ at 298 $\mathrm{K}$. The short or compensating wire is approximately $5 \mathrm{~cm}$ in length and its resistance varies from 10 to $45 \Omega$. To allow for thermal expansion over the range of operating temperatures the wires are mounted with a small weight attached at the bottom. The wires are mounted in the hard drawn (as received) state, because in the annealed state platinum has a rather low tensile strength [16].

\subsection{High Pressure Cell and Wire Supports}

The cell has been designed to withstand pressures of up to $70 \mathrm{MPa}$. In addition, if the cell is to be isothermal, its thermal conductivity should be high. Accordingly, the cell is made from beryllium copper, a material which meets these contradictory requirements best. Cell sizing, cell closure, and wire support are shown in figure 1 . The cell is quite similar to those used in other experiments in this laboratory [17-20]. It is mounted with the closure facing down. Three solid steel pins serve as electrical leads. They pass through the high pressure closure (stainless steel) and are insulated

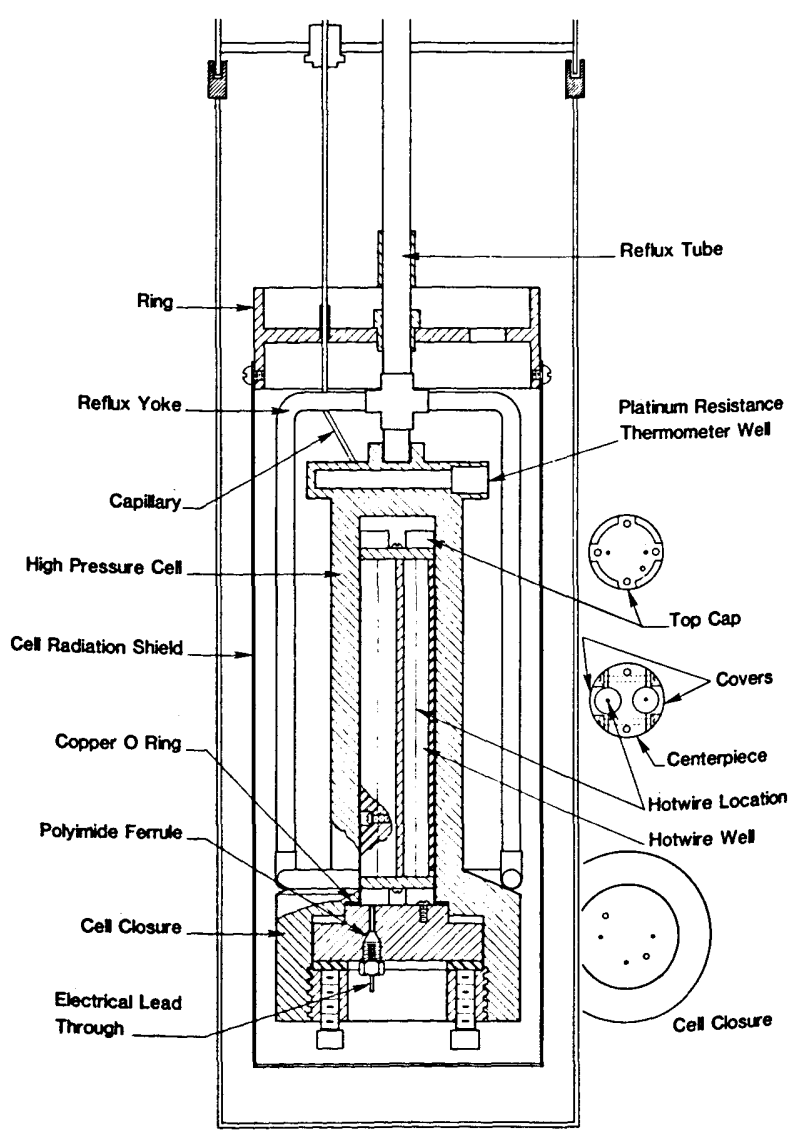

FigURE 1. The high pressure cell and wire support unit. 
from it using polymide ferrules [21]. The capillary which admits the sample is soldered into the top of the cell. Much of the interior of the cell is filled by the wire support unit which is made from copper and includes a centerpiece, two covers, a top and a bottom cap. The wire support unit is mounted on the high pressure closure. When assembled the wire support unit provides two cylindrical wells $9 \mathrm{~mm}$ in diameter and $11 \mathrm{~cm}$ long to accomodate the hot wires. Mounted in the top cap with friction fit are two $5 \mathrm{~mm} \mathrm{sec}$ tions of a small coaxial cable. The hot wires are soft soldered to the center leads of these coaxial sections. To the bottom of the long hot wire is soldered a short section of teflon covered wire which terminates in a 4-80 brass nut, the weight. The teflon covered section provides isulation between bottom cap and the extension of the long hot wire as well as centering for it. The long hot wire section is connected to one of the steel pins by a small loop of $12.7 \mu \mathrm{m}$ copper wire. The short hot wire is soft soldered to the other coaxial section in the top cap. To its bottom end a short length of copper wire centered in a second $4-80$ brass nut is soldered. The leads on the short hot wire side are completed by a loop of $12.7 \mu \mathrm{m}$ copper wire which connects to a $5 \mathrm{~cm}$ length of coaxial cable. This section of coax is friction fit into the bottom cap and is sufficiently rigid to stand alone. A second loop of copper connects this coax to the second steel pin. Long and short hot wire sections are connected together above the top cap with the center tap soldered in the middle of this connection. The center tap is a $11 \mathrm{~cm}$ long section of the coax which at the bottom end is connected to the third steel pin.

Liquid oxygen safety is one of the additional design considerations for the cell since the interior of the cell will be exposed to very high pressure $70 \mathrm{MPa}(10,000 \mathrm{psi})$ liquid. The materials directly exposed to liquid oxygen have been limited to beryllium copper, copper, stainless steel, silver, teflon, and a polyimide (kapton) all of which have been found to be "oxygen compatible" [22]. Cleaning procedures for cell, wire supports, capillary and sample handling system were extensive [23].

\subsection{The Wheatstone Bridge}

Precision measurements of resistance can be made by using a four lead technique or by using a Wheatstone bridge. In the present apparatus we follow the general development of the hot wire instrument pioneered by Haarman [2], de Groot, et al. [4], Assael, et al. [10] and de Castro, et al. [12] and use a Wheatstone bridge to measure resistances. End effect compensation is provided by placing the long hot wire in one working arm of the bridge and a shorter, compensating wire on the other. In contrast to other instruments where values of time are measured in the present instrument the voltage developed across the bridge is measured directly as a function of time with a fast response digital voltmeter (DVM). The DVM is controlled by a minicomputer which also handles the switching of the power and the logging of the data. The automation of the voltage measurement follows the work of Mani [3] who used a similar arrangement with a transient hot wire cell to measure resistance by the four lead technique rather than using a bridge.

Figure 2 shows the Wheatstone bridge circuit. Each arm of the bridge is designed to be $100 \Omega$, two arms $R_{1}$ and $R_{2}$ are standard resistors. The resistance in each of the other arms $R_{3}$ and $R_{4}$ is a composite of the hot wire, the leads into the cryostat and an adjustable ballast resistor. The leads are roughly $6 \Omega$ at room temperature and $2 \Omega$ when the cell is at $76 \mathrm{~K}$. The ballast resistors allow each working arm to be adjusted to a value of $100 \Omega$.

The measurement of thermal conductivity for a single point is accomplished in two phases. In the first phase the bridge is balanced as close to null as is practical. To start with, switch 1 is turned from dummy to the bridge while switch 2 is open. With a very small applied voltage, 0.1 Volts normally, and the cell essentially at constant temperature, the voltages are read on channels 0 through 7 . The lead, hot wire, and ballast resistances are calculated from the ratios of the appropriate channel voltgage to the voltage across the standard $100 \Omega$ resistor on channel zero. The ballasts are adjusted until each leg is approximately $100 \Omega$. Finally, with switch 2 closed, the bridge null is checked on channel 6 . The second phase incorporates the actual thermal conductivity measurement. The power supply is set to the applied power desired, switch 2 is closed, and switch 1 is switched from dummy to bridge. The voltage developed across the bridge as a function of time is read on channel 6 and stored. The basic data is a set of 250 readings taken at 3 ms intervals. Finally the voltage on channel 0 is read to determine the exact applied power, and the power is switched back to the dummy resistor.

\subsection{The Cryostat}

The cryostat for the apparatus, shown in figure 3 , is adapted from a general design first used in a PVT apparatus at this laboratory [24]. The cell is connected by the reflux tube to the inner refrigerant tank. The reflux tube is filled with gas which sometimes corresponds to the liquid used as the refrigerant. Varying the gas pressure changes the amount of refrigeration applied to the cell. A cooling yoke and ring insure that the refrigeration is applied primarily at the bottom of the cell. In this way a slight gradient can be maintained between cell top and cell bottom. To avoid convection inside the cell we normally maintain the cell bottom slightly colder than the cell top. The cell and its radiation shield is located in a vacuum environment. $A$ 


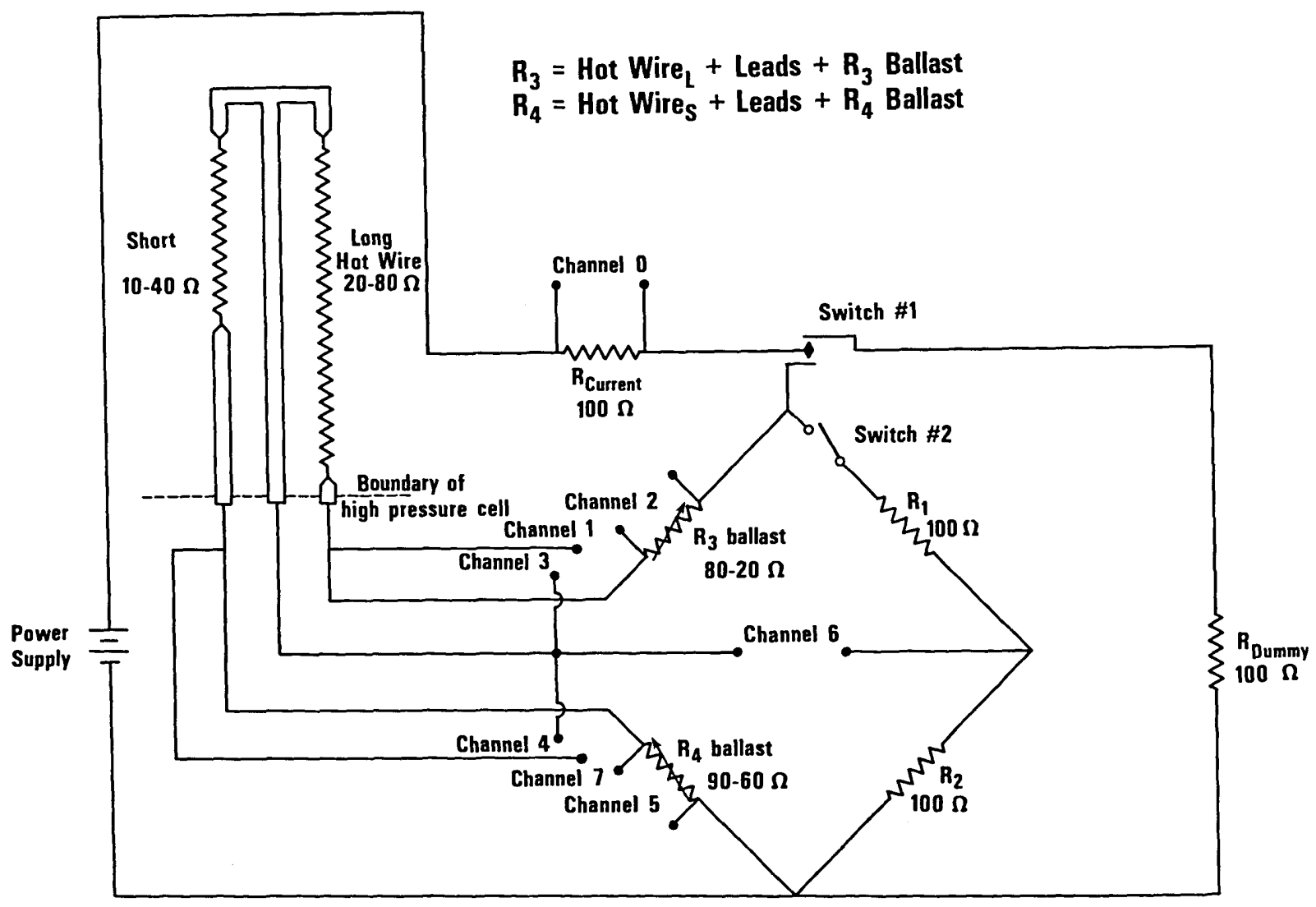

FIGURE 2. The Wheatstone bridge circuit.

tube which serves as the inner vacuum line also admits lead wires and the capillary into the inner vacuum space surrounding the cell. The leads are tempered on two rings, one is attached directly to the inner refrigeration tank, the other is the guard ring which is attached to the reflux tube. The cell radiation shield in turn is attached to the guard ring. The inner refrigerant tank is insulated by the outer vacuum system, which in turn is protected by the outer refrigerant, usually liquid nitrogen, in a dewar. All of the various access tubes, fill and vent lines, and vacuum lines pass through the mounting plate which rests on the mounting bracket attached to the wall. Cell alinement is achieved by adjustment of three set screws.

\subsection{Cryostat Temperature Control}

A diagram of this circuitry is shown in figure 4 . The cell temperature is monitored with the platinum resistance thermometer which is mounted in the cell. The PRT resistance is measured by the four lead method as a ratio against a 10 $\mathbf{\Omega}$ standard using a microvolt potentiometer, a stable cur- rent supply, and a high gain dc null detector. The amplified output of the detector is used in a feedback loop to provide power to the cell heater [25]. The ratio of power applied to cell top and cell bottom is monitored with a thermocouple and adjusted by hand. The temperature of the guard ring and cell radiation shield are maintained close to the cell temperature by the use of a second feedback loop. This loop includes a differential thermocouple and a low level dc voltage detector whose amplified output is routed to a power supply which in turn feeds the ring and shield heater. A separate, manual heater is mounted on the capillary. This heater is operated intermittently as needed. Its function is to ensure that the sample does not freeze in the capillary should by chance some unusual temperature conditions prevail at some spot in the capillary.

\subsection{Sample Handling and Vacuum Systems}

Block diagrams for both systems are shown in figure 5 . The vacuum system is conventional except for an automatic back pressure control with alarm and solenoid valve. These 
items were installed as a safety precaution should the silver plated copper 0-ring in the cell closure spring a leak and discharge oxygen into the vacuum space.

The sample handling system was also designed with oxygen in mind. It consists of the sample from a gas bottle, a molecular sieve to capture moisture, and a small diaphragm

HOTWIRE T.C. APPARATUS
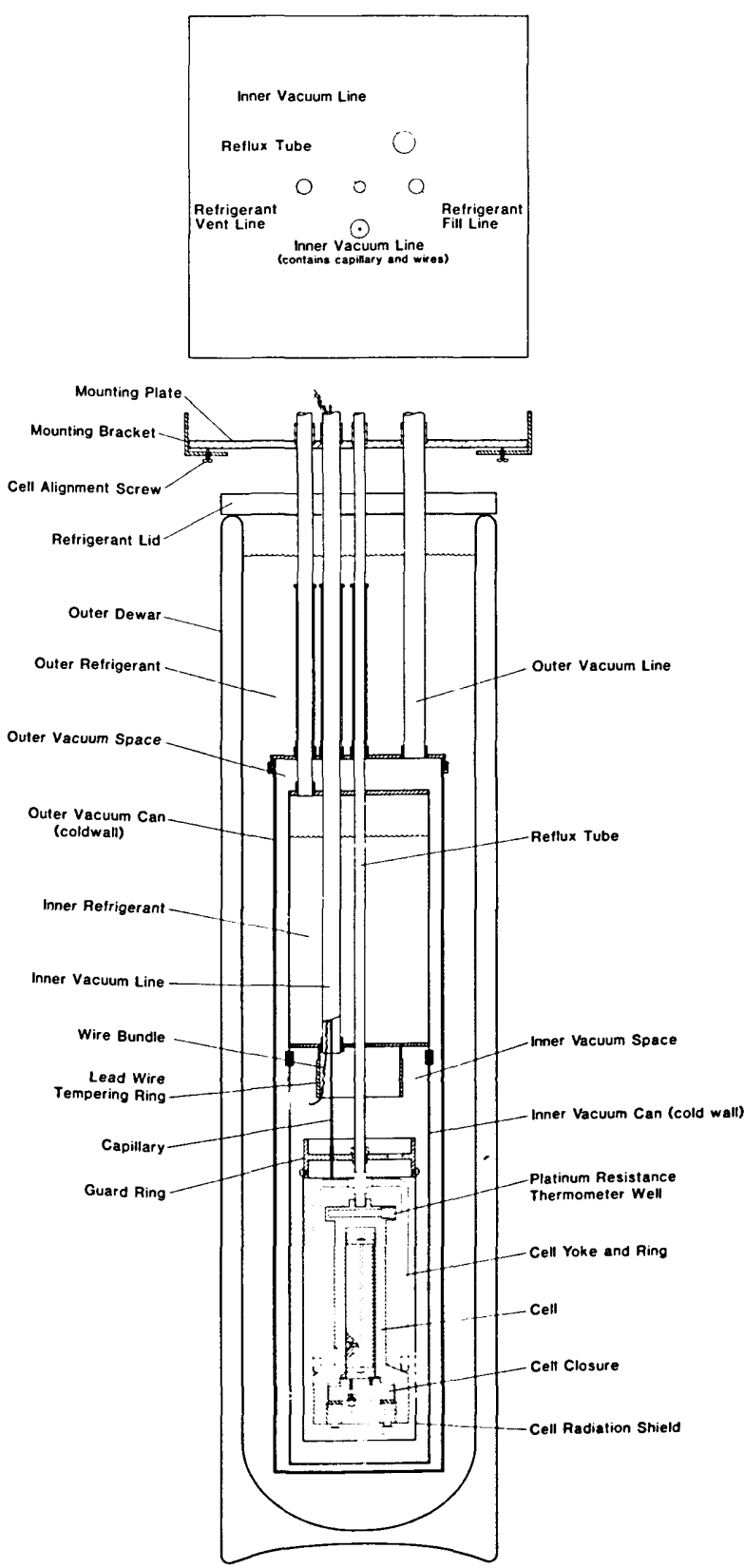

Figure 3. The cryostat. compressor as pressure intensifier. The compressor uses an oxygen compatible oil and has specially hardened check valves and seals. A pressure relief valve was provided in the cell pump-out line to protect against the possibility of an accidental oxygen overpressure, even though the forepump is charged with an oxygen compatible pump oil. With a few changes the sample system was able to handle a liquid sample, propane. Ordinarily the compressor requires an input pressure of about $5 \mathrm{MPa}(700 \mathrm{psi})$. However, if liquid is provided at the intake and sufficient time between strokes is allowed, then the compressor handles a liquid sample quite well. For propane, removing the molecular sieve and turning the supply bottle upside down ensured a direct flow of liquid.

\subsection{The Minicomputer}

A simplified block diagram of the minicomputer and its peripherals is shown in figure 6 . The CPU uses 18 bits per word with BASIC as the operational language. Program storage is on floppy disks, program input on the CRT, program listings are handled on the printer. Data can be displayed on the CRT and on the printer, and can be stored on floppy disk or magnetic tape. Input voltages, i.e., voltages to be read are routed from the 50 input channels by the multiplexer to the DVM where the analog to digital (A/D) conversion is effected. Output voltages, i.e., voltages to be used for experimental control are processed by the logic control unit where the digital to analog conversion takes place. These voltages are available at any of six output channels.

\section{Data Measured}

In the course of making a single thermal conductivity measurement a large number of variables are measured and recorded. The minicomputer program which controls the measurement is shown in appendix I. An example of a data file as assembled in the minicomputer and then transferred to magnetic tape is shown in appendix II. The first two lines of the data file are keyed in through the CRT. These lines contain the date, run and point number, the PRT reading from the microvolt potentiometer with the last digit repeated, the reading of the pressure gage, the barometer reading, the wire resistance for both long and short hot wire, the sums of lead and ballast resistance for both long and short hot wire sections, the time increment at which the voltage readings were taken, and lastly the voltage applied to the bridge. The remainder of the file contains the set of 250 voltage readings across the Wheatstone bridge.

\subsection{Cell Temperature}

The PRT is a standard capsule thermometer. It has been calibrated by the NBS temperature section. The voltage 


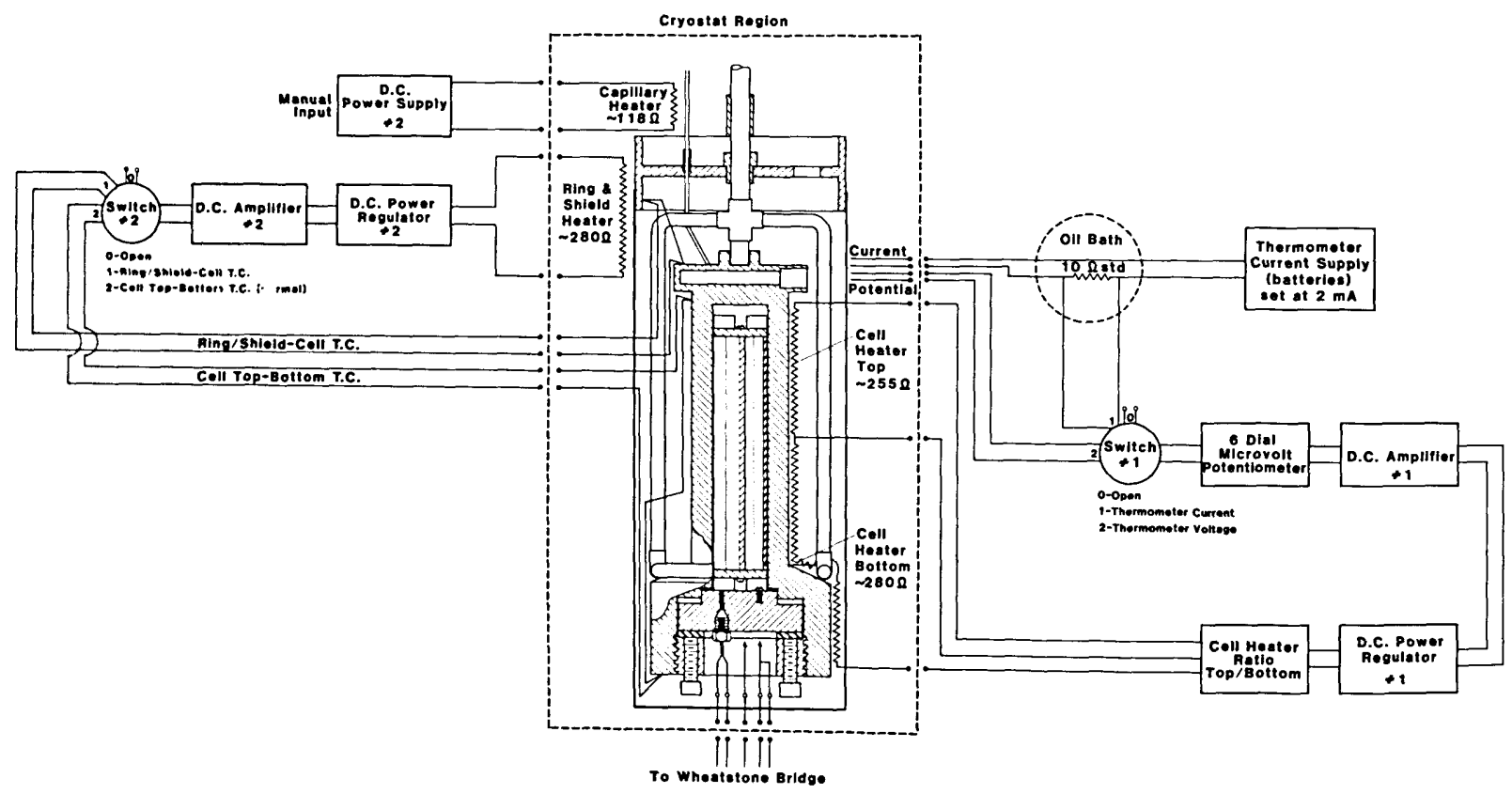

FIGURE 4. Block diagram of temperature measurement and cryostat control circuits.
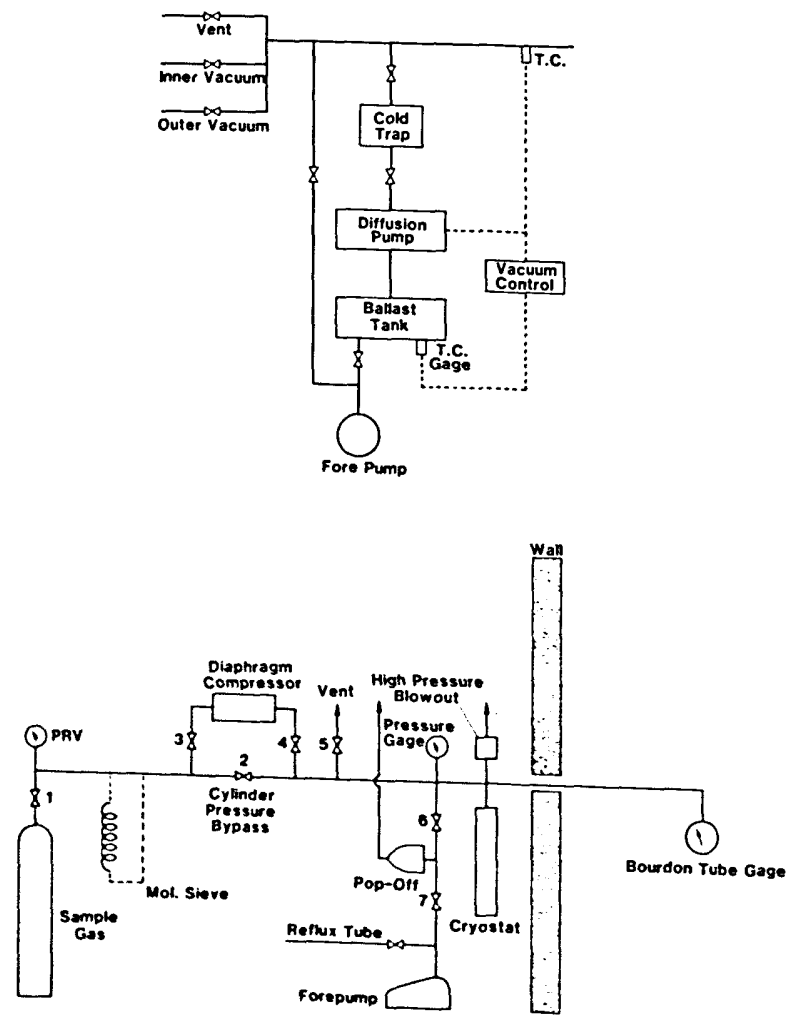

FIGURE 5. Vacuum and sample handling systems. 


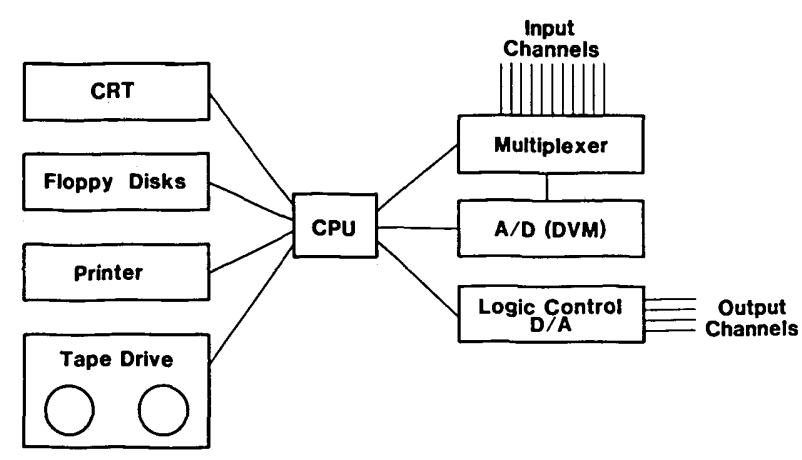

Figure 6. The minicomputer.

read across the $10 \Omega$ standard resistor is used to adjust the thermometer current so that a current of $1 \mathrm{ma}$ is flowing in the PRT circuit. A second voltage reading across the PRT proper allows its resistance to be calculated. The second voltage reading is the only value that is keyed into the CRT. The error in the cell temperature as established from a calibration of the microvolt potentiometer used is $0.001 \mathrm{~K}$ at $80 \mathrm{~K}$ increasing to $0.007 \mathrm{~K}$ at $292 \mathrm{~K}$.

\subsection{Cell Pressure}

The cell pressure is read with a commercial high precision steel bourdon tube. The unit was selected because it is "compatible" with high pressure oxygen. The unit is calibrated by the vendor with the calibration traceable to NBS. A digital readout is provided through an optical sensor, with the units of the readout in "counts." At the maximum pressure 96000 counts correspond to approximately 68 $\mathrm{MPa}$. At the higher pressures the bourdon tube displays hysteresis under loading as a function of time. It is this hysteresis that gives rise to the stated uncertainty of \pm 0.03 $\mathrm{MPa}$. The pressure gage calibration was represented by a low order polynomial for use in the data reduction program. The error attributable to this curve fit is well within the stated error of the gage. Vapor pressure checks of the gage at approximately $1 \mathrm{MPa}$ with both oxygen [26] and propane [27] confirm the calibration at the lower end of the pressure scale.

\subsection{Resisfances}

Direct resistance measurements are made while balancing the Wheatstone bridge. The resistances of the hot wires, of the leads, and of the ballast resistors are measured with the DVM set at the optimum gain. The resistance measurements are made using the four terminal method; the voltage across a standard $100 \Omega$ resistor defines the current in the circuit and the voltage reading across the unknown defines the resistance in question. In actual practice each voltage reading is the average of 100 individual readings. Each hot wire section measurement must be corrected for leads inside the high pressure cell which are short pieces of copper and steel wire. The corrections were calculated from wire dimensions and tabulated resistivities [28]. They are estimated to be $0.22 \Omega$ for the long hot wire section and $0.65 \Omega$ for the short hot wire section at room temperature. The corrections are handled in the data reduction program and are further adjusted for changes in bath temperature.

In order to obtain the temperature increase of the platinum wires from the corresponding resistance increase, we need to know the variation of resistance with temperature for both wires. It has been shown in the past $[8,12,13,29]$ that an in situ calibration of the wires is desirable and also that the resistances per unit length of both wires should be the same to within about 2 percent.

The wire resistances measured at essentially zero applied power in the balancing of the bridge together with the cell temperatures as determined from the platinum resistance thermometer are taken as the in situ calibration of the wires. During measurements on oxygen [26] some 1800 values were collected for each wire in the temperature range 76-320 K with pressures from atmospheric to about 70 $\mathrm{MPa}$. The resistance relation for each wire is represented by an analytical function of the type

$$
R(t)=A+B T+C T^{2}+D P
$$

where $T$ is the temperature in kelvin and $P$ the pressure gage reading. The pressure dependence is small but statistically significant and reflects the fact that the calibration measurements are made with a small applied voltage of 0.1 volts. Coefficients for eq (4) were determined in two ranges of temperature with some overlap in the range of the fits as shown in table 1 . The standard deviation of the resistance measurements as well as the equivalent temperature errors are shown in table 1 . The long wire has a length of 10.453 $\mathrm{cm}$ at room temperature, the short wire one of $5.143 \mathrm{~cm}$. Both wires have a nominal diameter of $0.001270 \pm$ $0.000001 \mathrm{~cm}$, thus the radius $a$ in eq (1) is $0.000625 \mathrm{~cm}$. If we use these values and the measured resistances we can calculate a resistivity of $10.07 \times 10^{-6} \Omega$-cm at $273.15 \mathrm{~K} \mathrm{com}$ pared to a best value of $9.60 \times 10^{-6} \Omega-\mathrm{cm}$ for an annealed high purity specimen [28]. The difference is ascribed to the hard drawn condition of our wires. The $\alpha$ of these wires, defined as $(R(373.15)-R(273.15) /(100 . \quad R(273.15))$ is 0.0037944 which is lower than the value 0.003925 required for use in an annealed platinum resistance thermometer [26]. Finally, we evaluate

$$
\sigma_{L}=\frac{R_{L}(T)}{\ell_{L}(T)} \text { and } \sigma_{s}=\frac{R_{S}(T)}{\ell_{S}(T)}
$$


Table 1. Cal ibration Constants of Wires.

\begin{tabular}{|c|c|c|c|c|c|c|c|c|c|}
\hline & $\begin{array}{c}\text { Temperature Range } \\
\text { of L.S. FIt }\end{array}$ & $\begin{array}{l}\text { Number of } \\
\text { Polnts in Flt }\end{array}$ & $\begin{array}{l}\text { Appllicable } \\
\text { Temperature Range }\end{array}$ & $A(\Omega)$ & $\theta\left(\Omega K^{-1}\right)$ & $\begin{array}{l}\text { Coefficients } \\
\qquad\left(\Omega \mathrm{K}^{-2}\right)\end{array}$ & $O\left(\Omega\left(M P_{O}\right)^{-1}\right)$ & $\begin{array}{l}\text { Standard Deviation } \\
\text { of Flt, One Sigma }\end{array}$ & $\begin{array}{l}\text { Equivalent } \\
\text { Error in T }\end{array}$ \\
\hline \multirow[t]{2}{*}{ Long wire } & $76-158 K$ & 707 & $77-150 \mathrm{~K}$ & -10.231206 & 0.3670809 & $-0.9903371 \times 10^{-4}$ & $-7.796325 \times 10^{-4}$ & $0.01 \Omega$ & $0.023 \mathrm{~K}$ \\
\hline & $142-305 k$ & 1684 & $150-315 K$ & -9.065472 & 0.3534445 & $-0.5923443 \times 10^{-4}$ & $-1.401463 \times 10^{-3}$ & $0.019 \Omega$ & $0.054 \mathrm{~K}$ \\
\hline \multirow[t]{2}{*}{ Short wire } & $76-158 x$ & 707 & $77-150 \mathrm{~K}$ & -5.057558 & 0.1823527 & $-0.5257280 \times 10^{-4}$ & $-4.144377 \times 10^{-4}$ & $0.01 \Omega$ & $0.059 \mathrm{~K}$ \\
\hline & $142-305 k$ & 1684 & $150-315 k$ & -4.346459 & 0.1740251 & $-0.2831553 \times 10^{-4}$ & $-6.565822 \times 10^{-4}$ & $0.011 \Omega$ & $0.065 \mathrm{~K}$ \\
\hline
\end{tabular}

Table 2. Wire Resistances as a Function of Temperature

\begin{tabular}{ccccccccc}
$\begin{array}{c}\text { Pressure } \\
\text { MPa }\end{array}$ & $\begin{array}{c}\text { Temperature } \\
\mathrm{K}\end{array}$ & \multicolumn{2}{c}{ Wire Resistances } & \multicolumn{2}{c}{ Wire Lengths } & \multicolumn{2}{c}{ Resistances/Unit Length } & $\begin{array}{c}\text { Percent } \\
\text { long, } \Omega\end{array}$ \\
short, $\Omega$ & 1ong, $\mathrm{cm}$ & short,cm & long, $\Omega / \mathrm{m}$ & short, $\Omega / m$ & difference \\
.1013 & 75.00 & 16.7427 & 8.3231 & 10.434 & 5.134 & 160.5 & 162.1 & -1.03 \\
.1013 & 100.00 & 25.4865 & 12.6519 & 10.436 & 5.135 & 244.2 & 246.4 & -.89 \\
.1013 & 125.00 & 34.1064 & 16.9150 & 10.438 & 5.136 & 326.8 & 329.4 & -.79 \\
.1013 & 150.00 & 42.6026 & 21.1124 & 10.440 & 5.137 & 408.1 & 411.0 & -.72 \\
.1013 & 175.00 & 50.9731 & 25.2407 & 10.442 & 5.138 & 488.1 & 491.3 & -.64 \\
.1013 & 200.00 & 59.2539 & 29.3259 & 10.444 & 5.139 & 567.3 & 570.7 & -.59 \\
.1013 & 225.00 & 67.4606 & 33.3756 & 10.447 & 5.140 & 645.8 & 649.3 & -.55 \\
.1013 & 250.00 & 75.5934 & 37.3900 & 10.449 & 5.141 & 723.5 & 727.3 & -.53 \\
.1013 & 273.15 & 83.0582 & 41.0758 & 10.451 & 5.142 & 794.7 & 798.8 & -.51 \\
.1013 & 275.00 & 83.6520 & 41.3690 & 10.451 & 5.142 & 800.4 & 804.5 & -.51 \\
.1013 & 300.00 & 91.6366 & 45.3126 & 10.454 & 5.143 & 876.6 & 881.0 & -.50 \\
.1013 & 325.00 & 99.5472 & 49.2208 & 10.456 & 5.144 & 952.1 & 956.8 & -.49
\end{tabular}

and compare $\sigma_{L}$ and $\sigma_{S}$ in the experimental range. Table 2 shows the percent difference between $\sigma_{L}$ and $\sigma_{S}$ as a function of $T$. It is apparent that for the lower temperatures the correction proposed by Kestin and Wakeham [8] would apply except that in this apparatus independent calibrations for both long and short hot wire are used.

\subsection{Time Increment}

The timing of the experiment is based on the internal clock of the minicomputer, a temperature stabilized quartz crystal oscillator that divides a second into roughly 20,000 parts. Available to the programmer is a real time clock which is incremented in milliseconds. During a run this clock is first zeroed, line 620 in appendix I, next 250 voltage readings are taken across the bridge, and finally the clock is read, line 670 in appendix I. The gain of the DVM is set before starting the voltage readings. There are 250 steps in the program loop, where each step includes reading the DVM, storing the result, and time for the computer to execute the step. The time required to execute the program loop is $755 \mathrm{~ms}$, which means that the DVM is read every 3.02 milliseconds. Separate timing runs establish the time necessary to read the clock as about $1 \mathrm{~ms}$. This means the time increment could be as small as $3.012 \mathrm{~ms}$. Actual calculations using the data reduction program show that for this variation in time increment the thermal conductivity results are affected by less than 1 part in 20,000 .

The time increment between readings of the DVM can be varied by inserting a delay of several $m s$ into the program loop. Increments of 5,10 , and $15 \mathrm{~ms}$ were tried. In general, the use of larger time increments simply reduces the num. ber of useful points for the thermal conductivity analysis since for nearly all fluid conditions the onset of convection occurs at around one second in this apparatus.

\subsection{Power Level}

The ideal analysis stipulates that the heat flux $q$, applied to the wire remains constant during a given run. Under experimental conditions $q$ is nearly ideal at room temperature, i.e., it varies by about two parts in 10000 . However, at the very lowest temperatures the $q$ will vary from beginning to end of a run by values up to several percent. To see why this is so, and to find the correction that has to be applied consider the following.

The power supply used provides a constant voltage at its terminals to a circuit which consists of a $100 \Omega$ standard resistor in series with the Wheatstone bridge. The effective bridge resistance is nominally $100 \Omega$ but changes as the run progresses. The voltage of the power supply is preset, it is known to an accuracy of $\pm 200 \mu \mathrm{V}$. The set value is entered 
through the key board, just prior to switching the power to the bridge. After the run is completed, but before the power is switched back to the dummy resistor, the voltage across the standard resistor, channel 0 in figure 2 , is read. The difference between this voltage and the preset one is the voltage applied to the bridge a short time after completion of the run. The difference is one of the items placed on magnetic tape, and it is used in the data reduction program to calculate the power applied to the bridge. The instantaneous heat flux is determined from the equation.

$$
\begin{gathered}
q(t)=I^{2} R / \mathcal{l}=\left[\dot{V}(t) /\left(R_{3}(t)+R_{4}(t)\right)\right]^{2}\left(R_{L}(t)+\right. \\
\left.R_{S}(t)\right) /\left(\ell_{\mathrm{L}}+\ell_{S}\right)
\end{gathered}
$$

where $V(t)$ is the voltage applied to the bridge, and $R_{3}$ and $R_{4}$ are defined in figure 2. The voltage $V(t)$, both hot wire legs of the bridge $R_{3}$ and $R_{4}$, and the hot wire resistances themselves change as a function of time. At room temperature the drop in the current is almost exactly offset by the rise in the hot wire resistances. At low temperatures the fractional change in the hot wire resistances predominates. As an extreme example consider a run in liquid propane at say $110 \mathrm{~K}$. For a $3 \mathrm{~K}$ rise in wire temperature the long hot wire rises by $1 \Omega$ from an initial value of $30 \Omega$, or 3.3 percent. This rise is only partially offset by the 0.7 percent drop in the hot wire current leaving a net rise in $q$ of 2.6 percent from $t=0$ to $\mathrm{t}=755 \mathrm{~ms}$. The range of valid times for a run is generally $t_{1}=150 \mathrm{~ms}, t_{2}=755 \mathrm{~ms}$. Over this range of times the variation in $q$ is less than the extreme case because a large part, 70 percent or so, of the resistance change of the hot wires occurs during the times not valid for the experiment. Nevertheless, the remaining variation in $q$ is significant and we apply a correction to account for it. We select. a time in the middle of the valid time interval $t_{\alpha}=\left(t_{1}+t_{2}\right) / 2$ and correct the experimental $\Delta T$ 's by the ratio of the instantaneous $q$ to the $q$ at the median time

$$
\Delta T(t)_{\text {corr }}=\Delta T(t)_{\text {raw }} * q\left(t_{i}\right) / q\left(t_{a}\right) \ldots
$$

$V(t)$ varies by about one part in 1000 over a run, and some calculation verified that $V(t)$ varies as the $\ln (t)$, and further that the value measured was actually achieved at the requisite time after the end of the run.

\subsection{Bridge Voltoges}

The voltages measured across the bridge, actually a measure of the bridge unbalance, are the basic data in this experiment. A typical set of 250 of these voltages for point No. 9044 is shown in appendix II and is plotted in figure 7. The general shape of this curve is logarithmic, as expected.

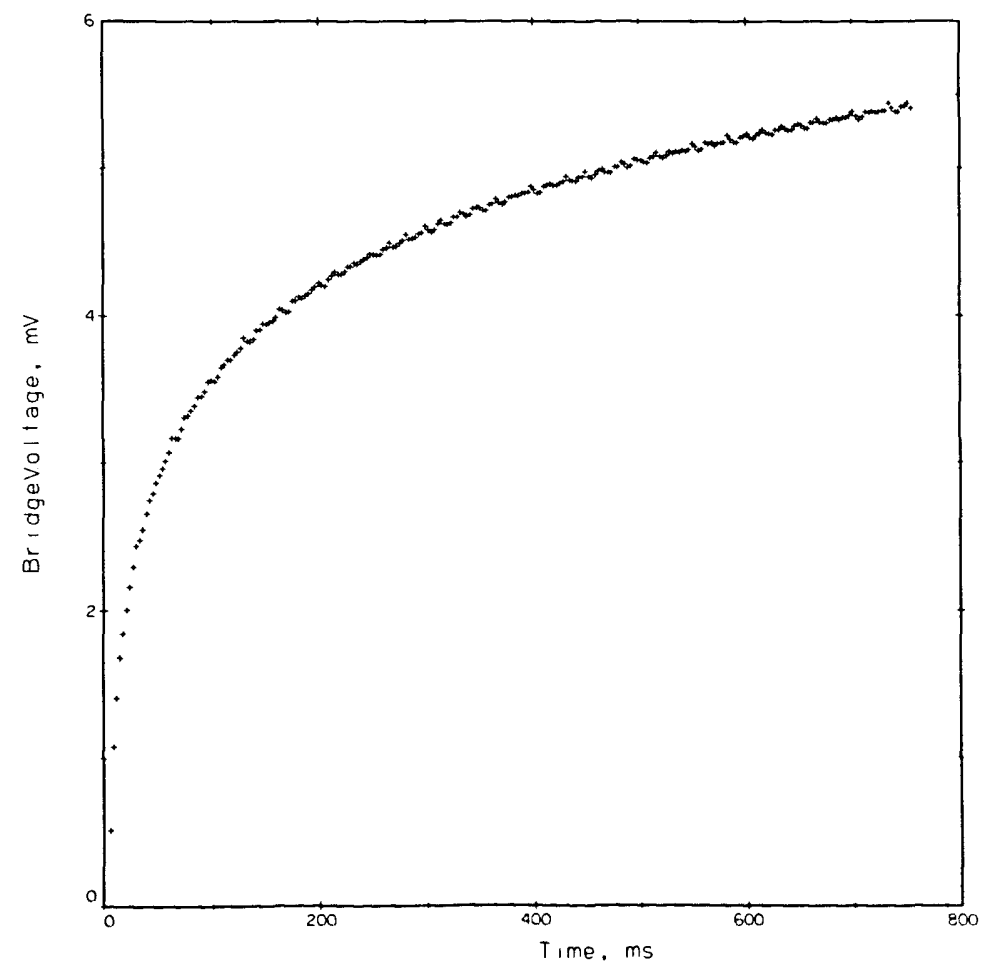

Ficure 7. Typical bridge voltages versus time, point 9044 , helium gas. 
Noise levels in these readings are evident. Considerable effort went into reducing the noise level, and also into tracing the source. The DVM, when shorted, exhibits an error band of $\pm 6 \mu \mathrm{V}$. When a $100 \Omega$ resistor is placed across the DVM, no applied power yet, the band increases to $\pm 17 \mu \mathrm{V}$. With the experimental system connected to the DVM the error band becomes $\pm 28 \mu \mathrm{V}$ which is roughly equivalent to $\pm .026 \mathrm{~K}$ in the $\Delta T$. Only a small part, some 20 or 30 percent, is due to $\mathrm{AC}$ pickup. Use of integrating or averaging DVM's will reduce the noise level at the expense, however, of a smaller number of measurements.

\section{Data Reduction}

A listing of the data reduction program used for helium is given in appendix III. Experimental values are read from the magnetic tape. Initial calculations and corrections include corrections for the bias of the DVM, corrections for the leads inside the high pressure cell, and an estimation of the instantaneous voltage applied to the bridge. The $\Delta T_{w}$ values are calculated from the voltages applied to the bridge, the offset or measured voltages across the bridge and the two hot wire calibrations. The bridge equation is solved repeatedly until the increases in the hot wire resistances together with the voltage applied to the bridge yield an offset voltage equal to the measured one. The various corrections to the $\Delta T_{w}$ are applied to obtain the $\Delta T$, and then the $\Delta T$ 's and $\ln (t)$ 's are passed to a least squares regression routine. Microfilm plots of both $\Delta T$ and the deviation of each measured point from the regression line versus $\ln (t)$ are set up. Typical examples again for point No. 9044 are shown in figures $8 \mathrm{a}$ and $8 \mathrm{~b}$. In the final steps of the data reduction program an equation of state is used to find the applicable density, the experimental thermal conductivity is compared to any previous correlation that might exist, and the results are printed.

A certain amount of judgement enters into the data reduction process particularly in the selection of $t_{1}$ and $t_{2}$, the range of times over which the least squares straight line regression is to be evaluated. The criterion for a valid result is that the $\Delta T$ values as plotted in the example, figure 8a, shall form a straight line versus the $\ln (t)$. The deviation plot as shown in figure $8 b$ is used to help determine the valid range of the least squares fit. For most experimental conditions $t_{1}=150 \mathrm{~ms}$ and $t_{2}=755 \mathrm{~ms}$. In both figures, $8 \mathrm{a}$ and $8 \mathrm{~b}$, the points plotted begin at index 11 or $t=33 \mathrm{~ms}$. The first 30 or so points are seen to fall somewhat below the straight line. By inspection the fit for point 9044 could have included an index as low as 41 or $t_{1}=124 \mathrm{~ms}$. In figure $8 \mathrm{~b}$ the standard deviation for the regression fit of point 9044 is roughly 0.2 percent, or at the $3 \sigma$ level 0.65 percent.

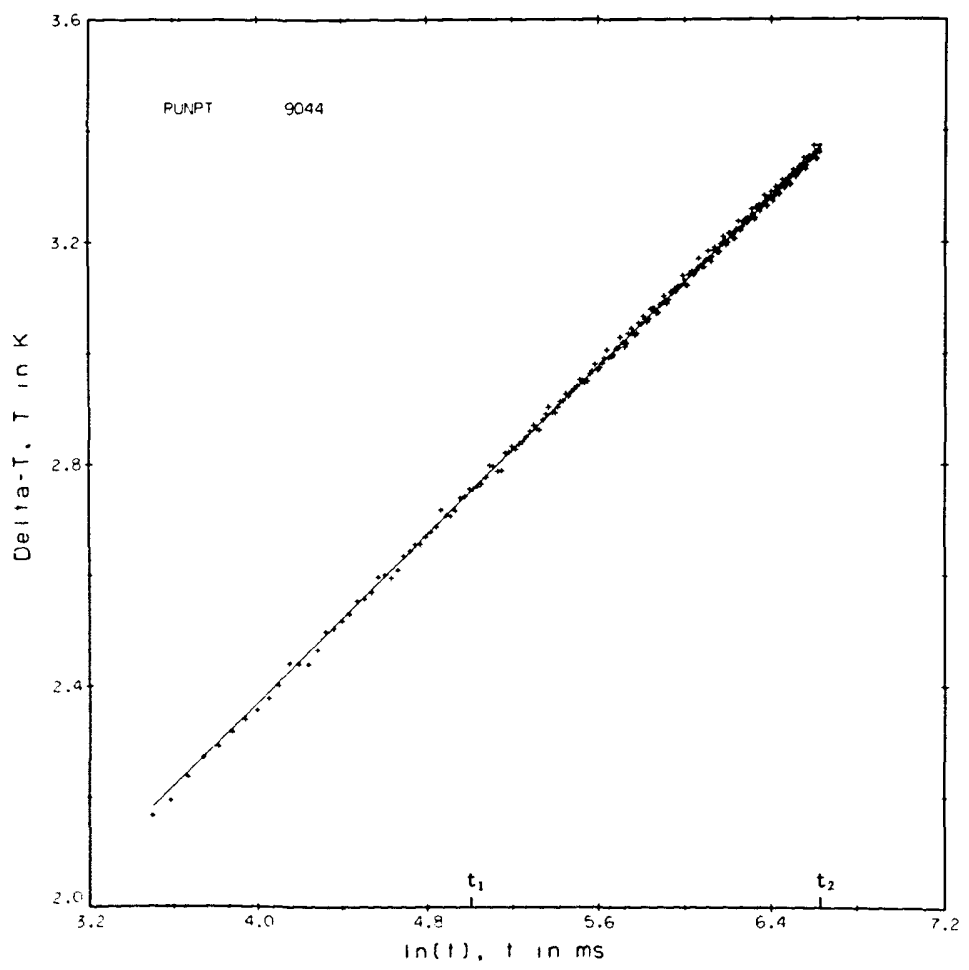

FIGURE 8a. Typical temperature rises versus the logarithm of time, point 9044 , helium gas. 


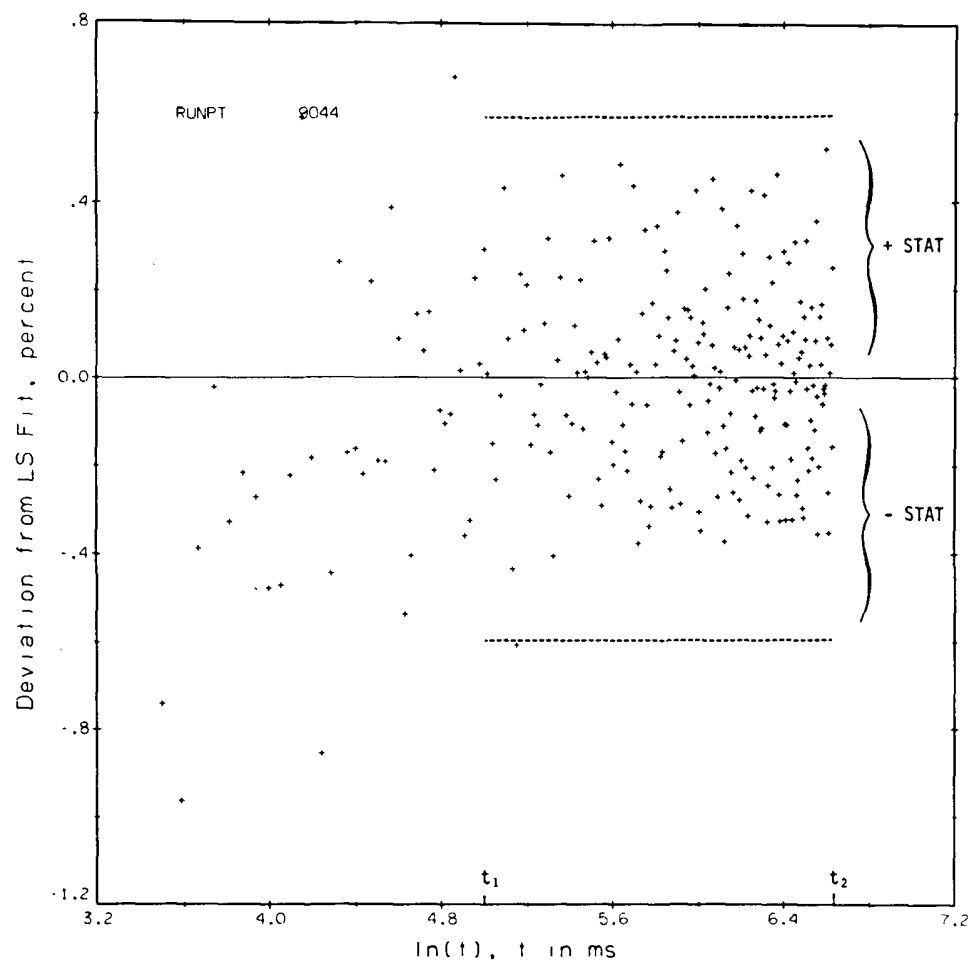

FIGURE 8b. Typical deviations of experimental temperature rises from the calculated straight line versus the logarithm of time, point 9044 , helium gas.

By implication, it is equally important to recognize and interpret nonstandard results obtained, so that invalid results can be identified and rejected. A description of several of the more interesting malfunctions follows. In figure 9a we see that the $\Delta T$ values are nearly constant toward the end of the run. This state of affairs depending on the state of the fluid sample is interpreted as (a) the apparatus is operating in the steady state mode, or (b) as the onset of convection in the run.

If a similar run at higher fluid densities is taken to much longer experimental times the plot is as shown in figure $9 \mathrm{~b}$. Here the effect of convection is clearly seen as a rapid cooling of the hot wires after the maximum $\Delta T$ is passed. In principle we could get a valid result for the transient hot wire by selecting $t_{1}=690 \mathrm{~ms}$ and $t_{2}=1353 \mathrm{~ms}$. However, the number of $\Delta T$ values useful for the straight line regression has now dropped to 50 . In practice it turns out that the applied power level, as seen in the resulting $\Delta T$ 's of 10 to 12 $\mathrm{K}$, was simply too large to be useful. The plot of figure 9c shows the effect of gas circulation within the cell. The precise cause is not known. Convection combined with thermal oscillations when the capillary cools are suspected reasons. From the plot it is clear that the wires experience a non-uniform temperature field and are subject to abrupt segments of convection cooling. Measurements with a plot of this type are rejected.
In figure 9d the DVM saturated toward the end of the run. By excluding the points for which the voltage readings are constant, and provided there are sufficient measurements to extract a straight line fit, a measurement of this type can be used. At the very lowest pressures (densities) in the vapor phase at temperatures much below the critical temperature some plots look like the one shown in figure $9 \mathrm{e}$. The physical interpretation of this run is that we see a Knudsen effect at short times and an outer boundary effect at the longer times. No valid range for the hot wire instrument exists and these results are rejected. In the region near the critical point the onset of convection occurs much more rapidly. Measurements in this fluid region have to be made at lower power levels and at shorter times. For the measurements on oxygen experimental times of $t_{1} \cong 33 \mathrm{~ms}$ and $t_{2} \cong 500 \mathrm{~ms}$ were found to be appropriate.

A second criterion which is used in accepting or rejecting experimental measurements is by considering the change in the measured thermal conductivity as the applied power, $q$, is varied. Examples are given in the sections on nitrogen and helium. In a general way this criterion suggests that measurements in which the final $\Delta T$ 's are larger than about $5 \mathrm{~K}$ are suspect. This includes most of the critical region where the results have to be evaluated quite carefully, almost on an individual point by point basis. 


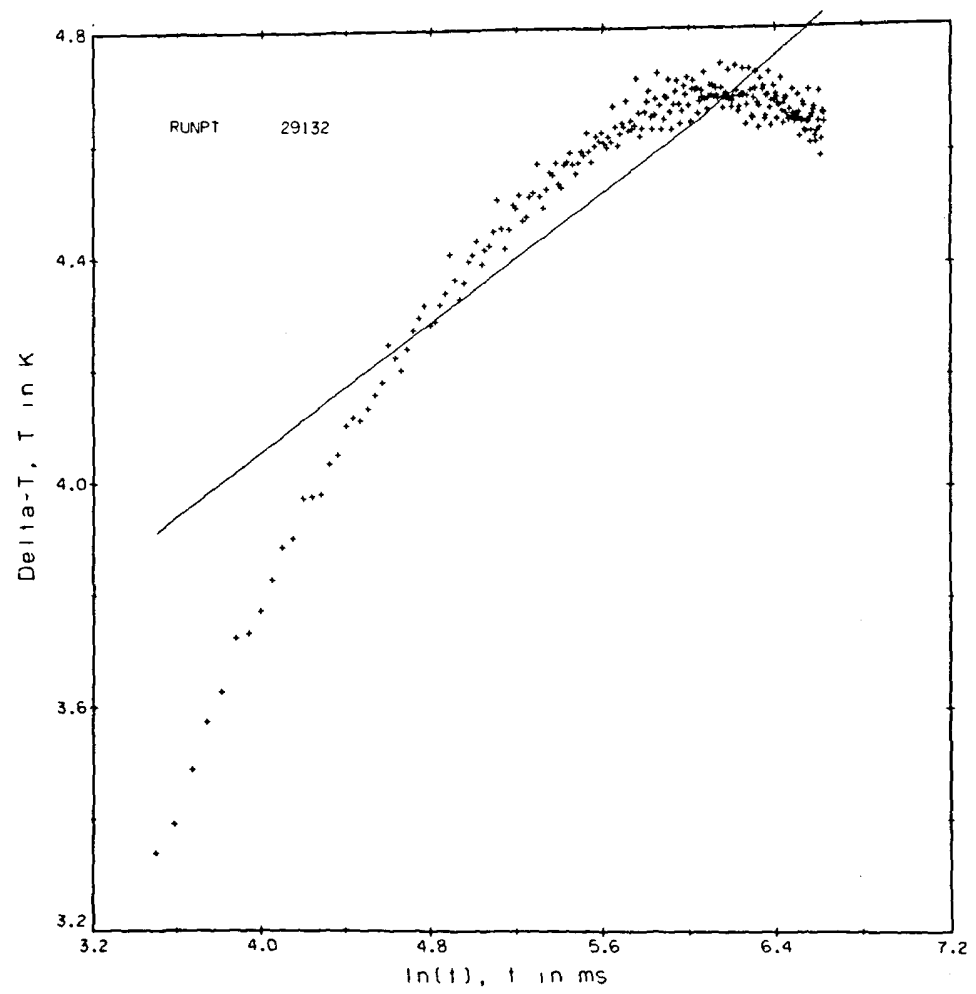

Figure 9a. Plots of experimental malfunctions. Point 29132, argon gas.

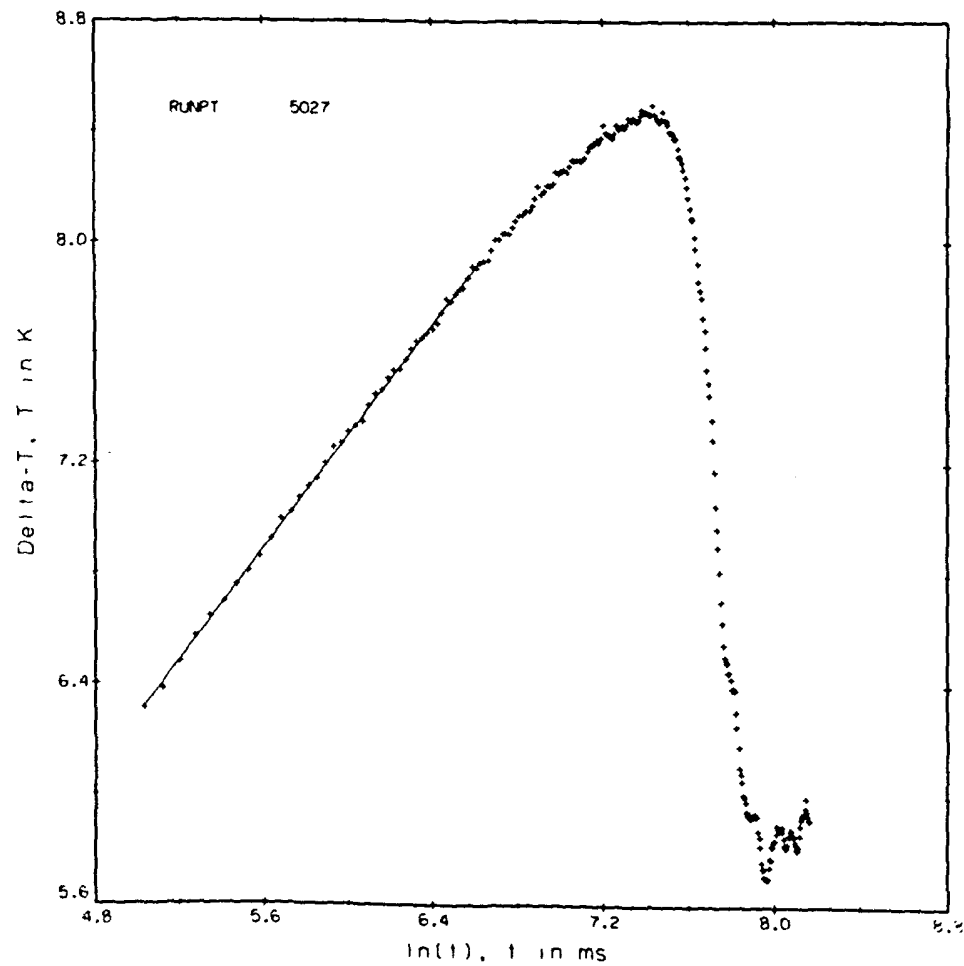

FIGURE 9b. Point 5027, nitrogen gas. 


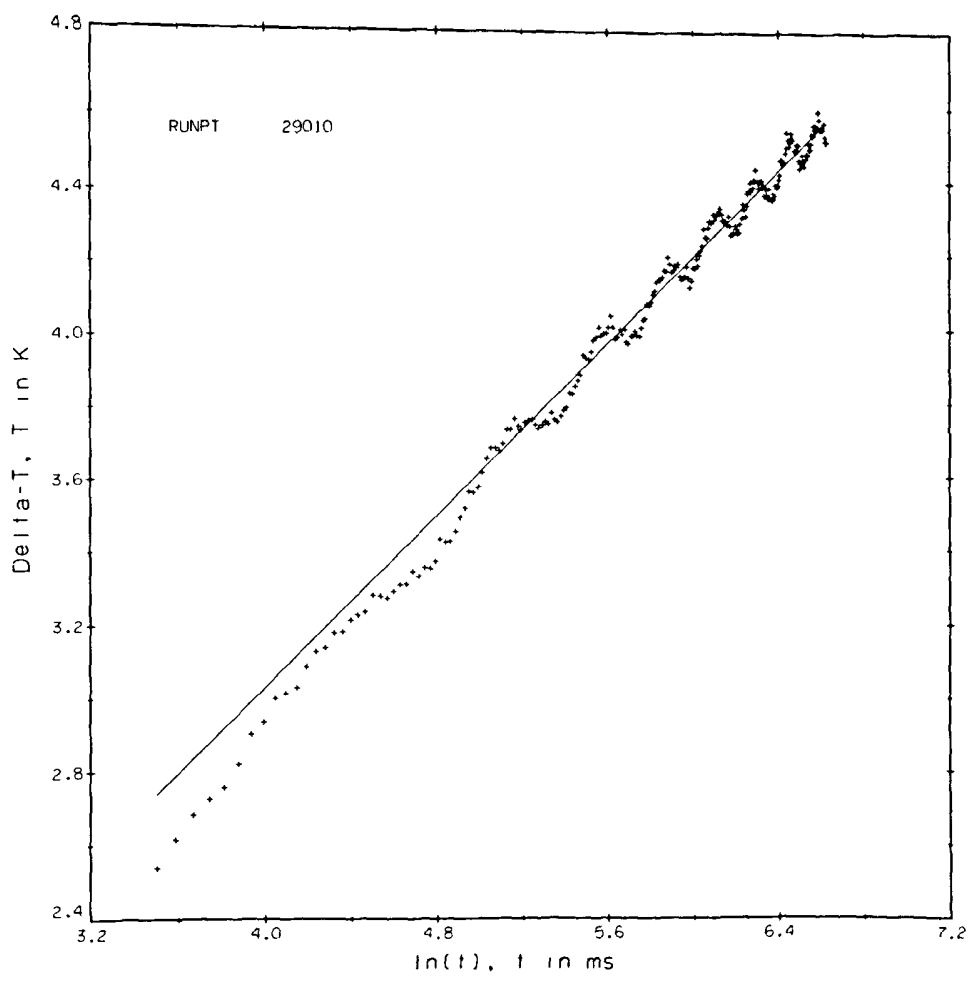

Figure 9c. Point 29010, argon gas.

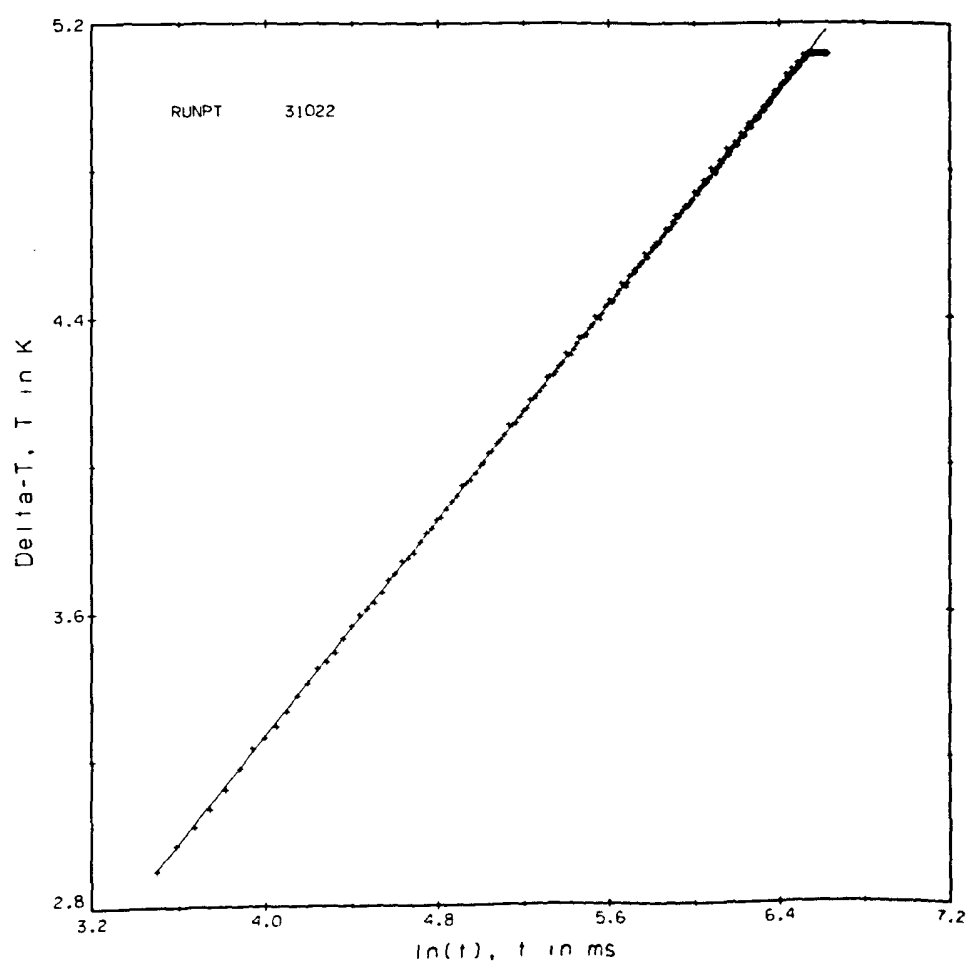

FIGURE 9d. Point 31022, propane liquid. 


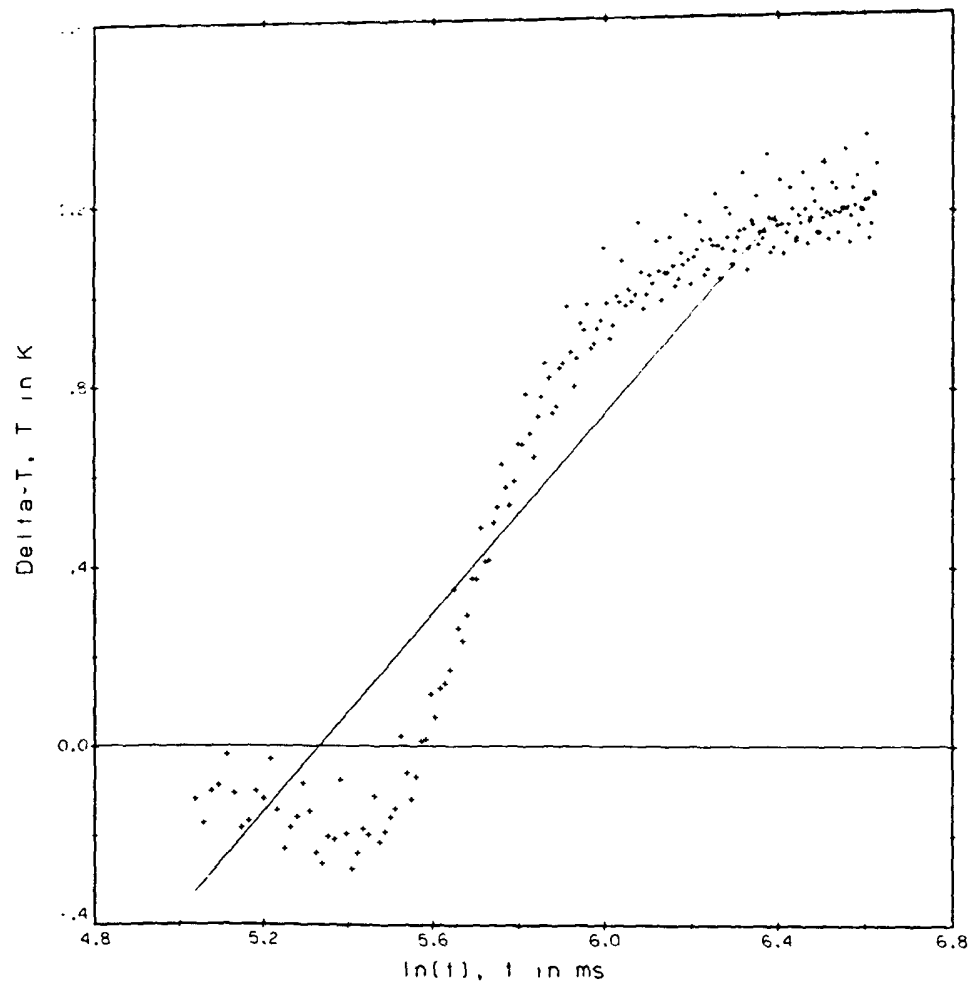

FIGURE 9e. Point 28003, oxygen vapor.

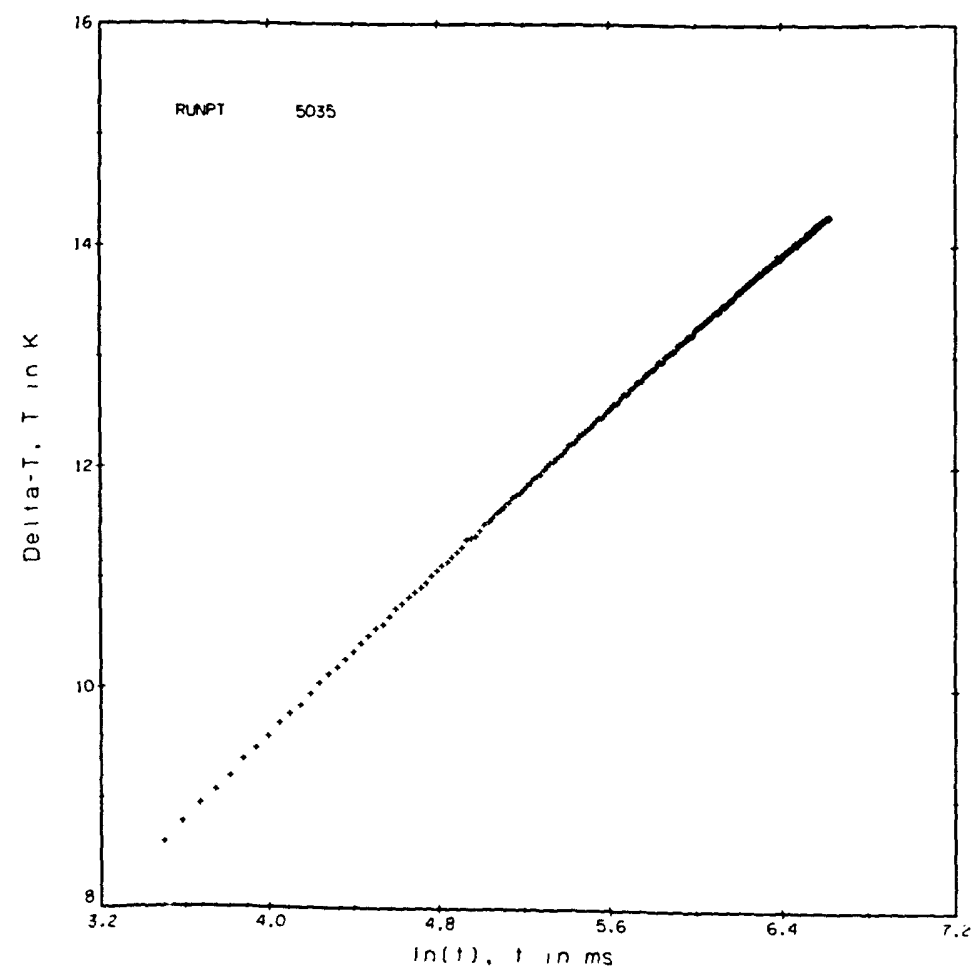

Ficure 9f. Point 5035, nitrogen gas. 


\section{Performance Verification}

\subsection{Nitrogen Results}

One of the gases selected for apparatus testing was nitrogen. Typical measurements on nitrogen are presented in table 3. There are two different sets of measurements. Run 4 is an abbreviated isotherm to check the functioning of the system as the pressure is varied. In contrast, all measurements of run 5 are taken at a single density while several of the pertinent apparatus parameters are varied.

Run 4, the pseudo-isotherm, was measured at temperatures between 297 and $301 \mathrm{~K}$ with pressures up to $68 \mathrm{MPa}$. At each pressure (density) level a minimum of four different power settings were used. The results, a total of 50 points at varying temperatures are shown in table 3 . For easy comparison with the results of others and using a fixed $d \lambda / d \mathrm{~T}$ of $0.00063 \mathrm{~W} / \mathrm{m} \cdot \mathrm{K}^{2}$ the results were shifted at the experimental densities to an even temperature of $300.65 \mathrm{~K}$ as shown in the next to last column of table 3 . The results so adjusted are represented with a curve fit of the type used by Clifford, et al. [31]

$$
\lambda=A+B \varrho+C Q^{2}+D_{\varrho}{ }^{3}
$$

The coefficients were determined as $A=0.02550, B=$ $0.000112, C=0.310567 \times 10^{-4}$, and $D=0.261641 \times 10^{-5}$ with $\lambda$ in $W / m \cdot K$ and $\varrho$ in $\mathrm{mol} / \mathrm{L}$. The standard deviation for the fit is $0.00022 \mathrm{~W} / \mathrm{m} \cdot \mathrm{K}$ which translates to roughly 0.5 percent in the middle of the density range. The experimental measurements as adjusted to $300.65 \mathrm{~K}$ and the curve fit are shown in figure 10 . Taking the curve fit of eq (8) as the base, the present results and those of others $[31,32,33]$ are compared in figure 11. When all results are considered together they span a range of 3 percent. The differences between the present results and those of Clifford, et al. [31] who use a transient hot wire system range between 1.3 and 2.3 percent, the differences to the more recent measurements of Assael, et al. [32] range from 1.1 to 1.7 percent. Differences between the present results and a published wide-range correlation for nitrogen [33] lie between 0.6 and 4.5 percent. Reference [33] serves as the source of the equation of state for nitrogen.

Run 5 was measured at the same nominal pressure, about 16.3 $\mathrm{MPa}$, with experimental temperatures varying from 297 to 309 K. For easy comparison these results are referred to a common temperature, $300.65 \mathrm{~K}$, as indicated above. However, they are further adjusted to a common density of $6.3 \mathrm{~mol} / \mathrm{L}$ using eq (8). The values so adjusted are shown in the last column of table 3 , and are plotted in figure 12 versus the power applied, $q$. The first 15 points, shown as circles in figure 12 , are repetitive measurements to establish the base of comparison. The mean of these 15 points is the straight line in the center of figure 12 while the lines above and below represent changes of one percent.

We indicated previously that the time increment can be varied. A series of such measurements was made on nitrogen gas with time delays of 5 and $10 \mathrm{~ms}$. The runs are shown in table 3 as points $5016-5028$. The actual time increment between voltage measurements is $9.02 \mathrm{~ms}$ for runs 5016-5020 and $14.02 \mathrm{~ms}$ for runs 5021-5028 compared to a normal time increment of $3.02 \mathrm{~ms}$. A plot of point 5027 is given in figure $9 \mathrm{~b}$, where the straight line segment indicates the range of times, $t_{1}=154.22 \mathrm{~ms}$ and $t_{2}=757.08 \mathrm{~ms}$, used to evaluate the result given in table 3 . If proper times $t_{1}$ and $t_{2}$ are selected, then runs of this type can yield valid results. However, the associated regression statistics deteriorate because a smaller number of points is available to the least squares analysis.

A second test involves larger than normal powers. The idea is to compare measurements made at one reference temperature with a very large power to measurements made at a higher reference temperature with a much smaller applied power, an overlapping of isotherms so to speak. For example a run at $T_{\text {ref }}=295 \mathrm{~K}$ and a power level to produce $\Delta T$ 's of around $15 \mathrm{~K}$ or a $T_{\text {exp }}$ of $310 \mathrm{~K}$ could be compared to a second run of $T_{\text {ref }}=307 \mathrm{~K}$ and a power level to produce $\Delta T^{\prime} \mathrm{s} \sim 4 \mathrm{~K}$ with a $T_{\text {ref }}$ also of $310 \mathrm{~K}$. The measurements taken are shown in table 3 as points $5031-$ 5035. The test fails because we can see a slight dependence on power level for the high powers in figure 12. The reason the test fails is because the plot of $\Delta T$ versus $\ln (t)$ instead of being a straight line is curved at the very large $\Delta T \mathrm{~s}$ in. volved, as shown in figure $9 \mathrm{f}$ for point 5035 . The test might become valid in the future, provided a reanalysis of the corrections to the experimental $\Delta T_{w}$ is made which allows for sufficiently large $\Delta T$.

A final experimental test involves the gradient along the high pressure cell. The cell is fitted with a thermocouple that measures the temperature difference from the top to the bottom of the cell. Nearly all runs were measured with the top of the cell slightly warmer than the bottom, about 10 to $15 \mathrm{mk}$. Test runs with the cell top hotter by $47 \mathrm{mk}$ are shown as points $5036-5040$ while similar measurements with the cell top colder by about $35 \mathrm{mk}$ are given by points 5041 - 5045. The results show that the thermal conductivities measured under these conditions vary by roughly 0.2 percent, which in view of the other uncertainties is negligible.

\subsection{Helium Results}

The rare gas selected initially was helium. Results obtained subsequently on argon have already been published [30]. For helium a single pseudo isotherm was measured at a nominal temperature of $307 \mathrm{~K}$ with pressures up to $68 \mathrm{MPa}$. 
Table 3. Thermal Conductivity of Nitrogen Near $300 \mathrm{~K}$.

Adjusted Thermal Conductivity

Thermal

Run Pt. Pressure

69.123

69.124

69.124

69.123

69.125

69.125

61.132

61.133

61.128

61.131

54.586

54.588

54.588

54.588

47.903

47.903

47.905

47.905

40.607

40.608

40.609

40.609

33.596

33.596

33.596

33.596

26.643

26.642

26.643

26.642

19.700

19.700

19.700

19.700

19.700

12.708

12.708

12.708

12.708

5.681

5.681

5.681

5.681

5.681

5.681

1.430

1.430

1.429

1.429

1.429

4050

5001

5002

5003

5004

5005

5006

5007

5008

5009

5010

5011

5012

5013

5014

5015
16.327

16.327

16.327

16.327

16.327

16.328

16.328

16.329

16.329

16.329

16.329

16.329

16.329

16.329

16.329

$\mathrm{K}$

297.004

297.439

298.096

298.759

299.583

300.322

298.146

298.905

299.709

300.741

298.026

298.703

299.475

300.334

300.778

299.771

298.863

298.042

297.907

298.705

299.584

300.704

298.229

299.023

300.028

301.176

297.741

298.530

299.522

300.611

300.643

299.992

298.934

297.950

297.532

297.418

298.319

299.457

300.749

301.332

300.556

299.102

297.843

299.714

298.464

299.675

298.299

297.129

297.703

298.984

297.649

298.523

299.492

300.657

301.440

301.373

300.632

299.496

298.426

297.614

297.512

298.293

299.270

300.472

301.184
Density Power mol/h

$\mathrm{w} / \mathrm{m}$

$17.5101 \quad .14023$

$17.4916 \quad .20067$

$17.4635 \quad .27180$

17.4351 .35381

$17.4003 \quad .44662$

$17.3691 \quad .55006$

$16.4493 \quad .27174$

$16.4166 \quad .35371$

$16.3813 \quad .44650$

$16.3376 \quad .54992$

$15.5156 \quad .23468$

$15.4863 \quad .31117$

$15.4528 \quad .39862$

$15.4156 \quad .49695$

$14.3096 \quad .49683$

$14.3531 \quad .39857$

$14.3927 \quad .31119$

$14.4285 \quad .23469$

$13.0618 \quad .20044$

$13.0277 \quad .27163$

$12.9903 \quad .35361$

$12.9427 \quad .44624$

$11.4980 \quad .20061$

$11.4655 \quad .27208$

$11.4247 \quad .35423$

$11.3782 \quad .44717$

$9.7001 \quad .14033$

$9.6705 \quad .20078$

$9.6340 \quad .27210$

$9.5939 \quad .35421$

$7.4708 \quad .31180$

$7.4902 \quad .27212$

$7.5221 \quad .20073$

$7.5521 \quad .14029$

$7.5651 \quad .11414$

$5.0731 \quad .09066$

$5.0546 \quad .14029$

$5.0314 \quad .20079$

$5.0054 \quad .27209$

$2.2732 \quad .23508$

$2.2798 \quad .20076$

$2.2923 \quad .14028$

$2.3032 \quad .09064$

$2.2870 \quad .16920$

2.2975

.5751

.5779

.5799

.5788

.5761

6.3985

6.3757

6.3507

6.3209

6.3010

6.3030

6.3218

6.3511

6.3787

6.3999

6.4028

6.3824

6.3571

6.3263

6.3083

.20090

.31195 $\mathrm{W} / \mathrm{m} \cdot \mathrm{K}$

06868

.06868

.06821

.06829

.06845

.06831

.06344

.06379

.06333

.06347

.05971

.05962

.05980

.05977

.05555

.05551

.05570

.05555

.05049

.05078

.05092

.05104

.04616

.04600

.04636

.04633

.04128

.04135

.04199

.04154

.03707

.03693

.03695

.03678

.03676

.03223

.03212

.03216

.03238

.02837

.02830

.02816

.02813

.02821

.02807

.02605

.02582

.02618

.02581

.02608

.03439

.03453

.03484

.03489

.03508

.03485

.03495

.03467

.03471

.03459

.03447

.03453

.03463

.03468

.03482 
Table 3. (Continued)

\begin{tabular}{|c|c|c|c|c|c|c|c|c|}
\hline Run Pt. & $\begin{array}{l}\text { Pressure } \\
\quad \mathrm{MPa}\end{array}$ & $\begin{array}{c}\text { Temperature } \\
\mathbf{K}\end{array}$ & $\begin{array}{l}\text { Density } \\
\mathrm{mol} / \mathrm{L}\end{array}$ & $\begin{array}{l}\text { Power } \\
\mathrm{W} / \mathrm{m}\end{array}$ & $\begin{array}{l}\text { Thermal } \\
\text { Conductivity } \\
\text { W/m・K }\end{array}$ & STAT & $\begin{array}{c}\text { with } T=300.65 \mathrm{~K} \\
\mathrm{~W} / \mathrm{m} \cdot \mathrm{K}\end{array}$ & $\begin{array}{c}\text { with } T=300.65 \mathrm{~K} \\
\text { and } \rho=6.3 \mathrm{~mol} / \mathrm{L} \\
W / \mathrm{m} \cdot \mathrm{K}\end{array}$ \\
\hline 5016 & 16.330 & 297.460 & 6.4043 & .09069 & .03505 & .060 & .03525 & .03506 \\
\hline 5017 & 16.330 & 298.264 & 6.3834 & .14035 & .03459 & .033 & .03474 & .03459 \\
\hline 5018 & 16.330 & 299.300 & 6.3566 & .20085 & .03481 & .019 & .03490 & .03480 \\
\hline 5019 & 16.330 & 300.512 & 6.3255 & .27213 & .03476 & .012 & .03477 & .03472 \\
\hline 5020 & 16.330 & 301.228 & 6.3074 & .31179 & .03470 & .009 & .03466 & .03465 \\
\hline 5021 & 16.329 & 296.862 & 6.4199 & .05183 & .03397 & .186 & .03421 & .03399 \\
\hline 5022 & 16.329 & 297.554 & 6.4017 & .09073 & .03459 & .081 & .03479 & .03460 \\
\hline 5023 & 16.329 & 298.358 & 6.3807 & .14043 & .03436 & .041 & .03450 & .03435 \\
\hline 5024 & 16.329 & 299.454 & 6.3524 & .20091 & .03447 & .024 & .03455 & .03445 \\
\hline 5025 & 16.329 & 300.573 & 6.3235 & .27225 & .03468 & .014 & .03468 & .03464 \\
\hline 5026 & 16.329 & 302.013 & 6.2871 & .35420 & .03497 & .011 & .03488 & .03490 \\
\hline 5027 & 16.329 & 303.570 & 6.2483 & .44706 & .03505 & .009 & .03487 & .03496 \\
\hline 5028 & 16.329 & 305.150 & 6.2095 & .55073 & .03486 & .010 & .03458 & .03474 \\
\hline 5031 & 16.328 & 301.848 & 6.2910 & .35473 & .03465 & .008 & .03457 & .03459 \\
\hline 5032 & 16.328 & 303.341 & 6.2537 & .44782 & .03481 & .006 & .03464 & .03472 \\
\hline 5033 & 16.328 & 305.077 & 6.2109 & .55174 & .03514 & .005 & .03486 & .03502 \\
\hline 5034 & 16.328 & 306.934 & 6.1660 & .66648 & .03509 & .004 & .03469 & .03493 \\
\hline 5035 & 16.327 & 308.967 & 6.1175 & .79195 & .03528 & .003 & .03476 & .03509 \\
\hline 5036 & 16.333 & 297.573 & 6.4025 & .09074 & .03478 & .037 & .03497 & .03478 \\
\hline 5037 & 16.333 & 298.377 & 6.3815 & .14047 & .03471 & .019 & .03485 & .03470 \\
\hline 5038 & 16.333 & 299.450 & 6.3537 & .20096 & .03479 & .011 & .03487 & .03477 \\
\hline 5039 & 16.333 & 300.685 & 6.3222 & .27231 & .03488 & .007 & .03488 & .03484 \\
\hline 5040 & 16.333 & 301.270 & 6.3073 & .31209 & .03483 & .006 & .03479 & .03478 \\
\hline 5041 & 16.337 & 297.448 & 6.4073 & .09066 & .03435 & .034 & .03455 & .03435 \\
\hline 5042 & 16.337 & 298.207 & 6.3874 & .14029 & .03464 & .019 & .03479 & .03463 \\
\hline 5043 & 16.337 & 299.265 & 6.3600 & .20074 & .03469 & .011 & .03478 & .03467 \\
\hline 5044 & 16.338 & 300.475 & 6.3293 & .27202 & .03477 & .007 & .03478 & .03473 \\
\hline 5045 & 16.338 & 301.173 & 6.3115 & .31171 & .03483 & .006 & .03480 & .03478 \\
\hline
\end{tabular}

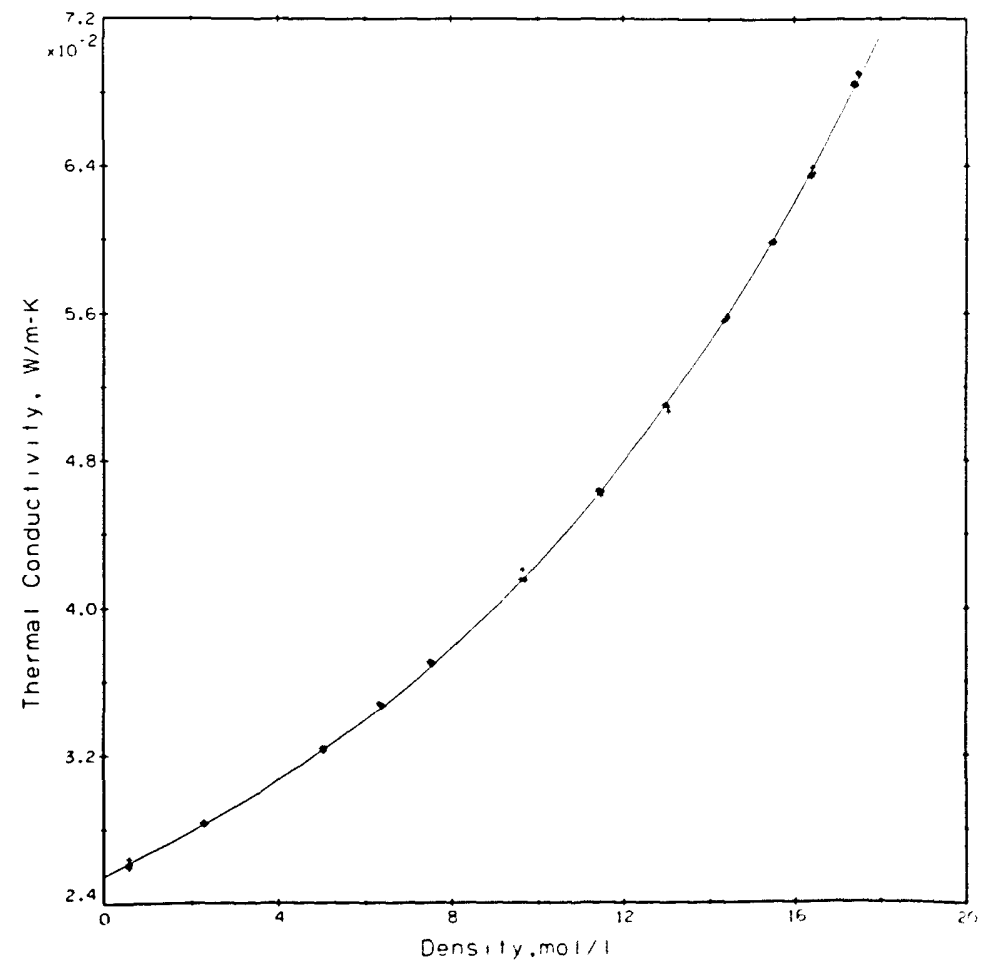

FiguRE 10. Nitrogen measurements shifted to $300.65 \mathrm{~K}$ with curve fit, eq (8). 


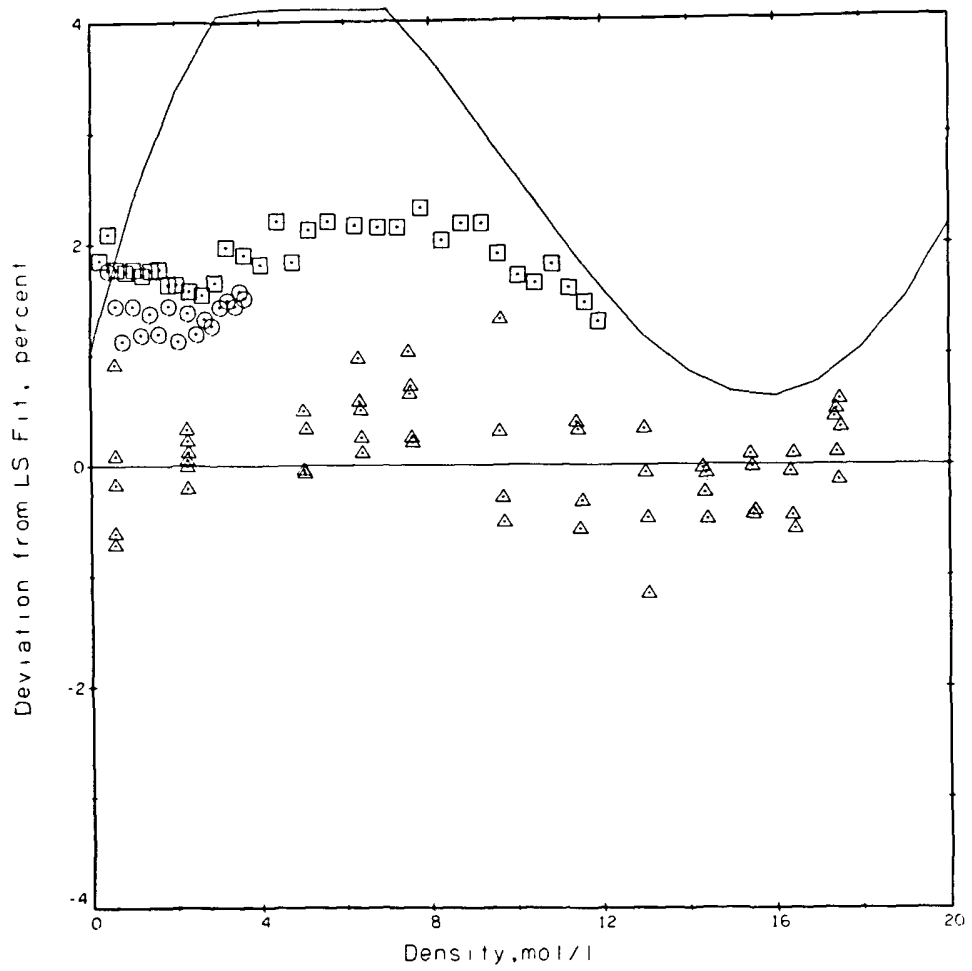

FiguRE 11. Comparison of the present results with those of others for nitrogen at $300.65 \mathrm{~K}$. Base line eq (8), $\Delta$ this paper, $\square$ Clifford, et al. [31], $\bigcirc$ Assael, et al. [32], — Hanley, et al. [33] correlation.

At each pressure (density) level two different power settings were used, while at three selected densities a larger range of power was covered. The results, a total of 77 points at varying temperatures are shown in table 4 . For easy comparison with the results of others and using a fixed $d \lambda / d T$ of $0.00035 \mathrm{~W} / \mathrm{m} \cdot \mathrm{K}^{2}$ the results were shifted at the experimental densities to a temperature of $300.65 \mathrm{~K}$ as shown in the last column of table 4 . The results so adjusted are represented with a curve fit of the same type as used on argon earlier.

$$
\lambda=A+B \varrho+C\left\{e^{0.13 \rho}-1.0\right\}
$$

The coefficients were determined as $A=0.153099, B=$ $0.108257 \times 10^{-2}$, and $C=0.613662 \times 10^{-3}$ with $\lambda$ in $\mathrm{W} / \mathrm{m} \cdot \mathrm{K}$ and $\varrho$ in $\mathrm{mol} / \mathrm{L}$. The standard deviation for the fit is $0.00049 \mathrm{~W} / \mathrm{m} \cdot \mathrm{K}$ which translates to roughly 0.6 percent at the 95 percent confidence level or 0.9 percent at the 99 percent confidence level. In other words, of the 77 measurements 71 lie within \pm 0.5 percent of the fitted curve. The experimental measurements as adjusted to $300.65 \mathrm{~K}$ and the curve fit are shown in figure 13. The densities at which a larger variety of power settings was measured are easily noted in figure 13 as $5.7,11.5$, and $19.6 \mathrm{~mol} / \mathrm{L}$. Taking the curve fit of eq (9) as the base, the present results and those of others $[7,34,35,36,37]$ are compared in figure 14. These results span a range of \pm 2 percent. The deviations between the present results and those of Le Neindre, et al. [34], Johannin, et al. [35], and Ho and Leidenfrost [36] are a nominal 1 percent or less. The differences between the present results and those of Kestin, et al. [7], who also use a transient hot wire system, range between 1.3 and 1.9 percent, while the differences between the present results and a published wide-range correlation for helium [37] also lie between 1 and 2 percent. Differences between the present results and the most recent ones of Assael, et al. [10], who also use a transient hot wire system, range from 1.0 to 1.7 percent. The source used as equation of state for obtaining the densities of helium is [37].

Finally, we apply a test that has not been applied extensively to other transient hot wire systems. In analogy to a flat plate steady state thermal conductivity apparatus [38] we insist that the measured thermal conductivity in the present apparatus should be independent of the applied power. Figure 15 shows the measurements for helium gas at $19.6,11.5$, and $5.7 \mathrm{~mol} / \mathrm{L}$ plotted as a function of the applied 


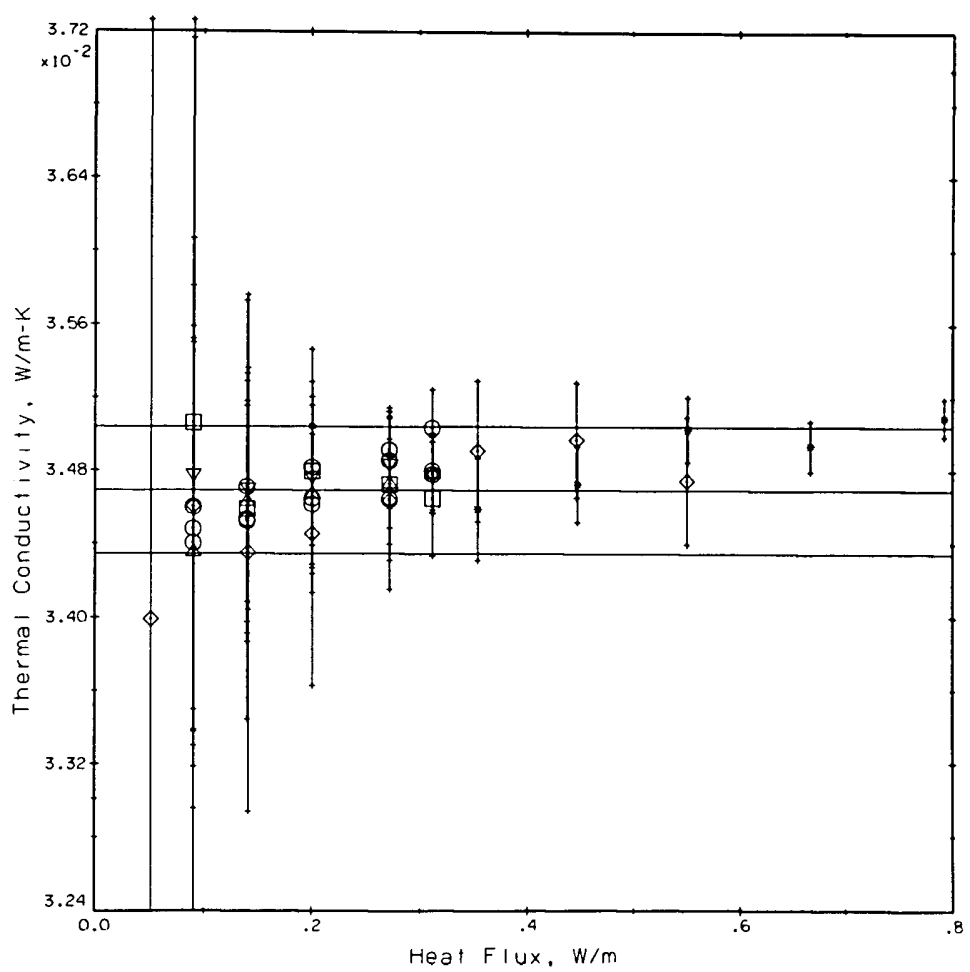

Ficure 12. Measured thermal conductivity as a function of the applied power. Apparatus tests with nitrogen gas.

$O$ normal measurements, $\Delta$ cell top cold, $\nabla$ cell top hot

$\square 5 \mathrm{~ms}$ delay, time increment $9.02 \mathrm{~ms}$

$\diamond 10 \mathrm{~ms}$ delay, time increment $14.02 \mathrm{~ms}$

* larger than normal powers.

power. Whereas $q$ changes by a factor of nearly five no dependence of the measured conductivity on power level is discernible. For reference, the values of the curve fit (eq (9)) plus or minus 0.5 percent are shown as three straight lines for each density in figure 15 . The error bars for each point are those originating from the regression straight line fit for each point, see column STAT in table 4.

\subsection{Cell Alinement}

During the construction of the apparatus we sought to keep the cell in vertical alinement to insure that convection in the cell would be delayed as long as possible. Later we sought to verify the alinement by a series of experimental measurements, some 162 points with oxygen gas as a sample at a pressure near $10 \mathrm{MPa}$ and a temperature of around 240 $K$. The position of each cell alinement screw was varied in turn by a measured amount. For each setting of the screws a series of seven to nine measurements were taken varying the applied power, $q$. If the cell is out of alinement the measured thermal conductivity increases. The increase is more pronounced at the higher power levels. The proper setting for the alinement screws occurs when the measured results are most nearly independent of $q$ as illustrated in figure 15 . The final settings chosen were nearly identical to those first achieved during construction of the apparatus. In fact, the measurements on helium, Run No. 9, were taken four months before the series on alinement, Run No. 19.

\subsection{Other Tests}

Tests were run on nitrogen gas at room temperature with only a single hot wire in the bridge. The circuit was rewired so that either $R_{4}$ or $R_{3}$, see figure 2 , were replaced by yet another $100 \Omega$ standard resistor. The data reduction program had to be modified accordingly. The results were evaluated only on the minicomputer, and are relative to similar 
Table 4. Thermal Conductivity of Hellum Near $300 \mathrm{~K}$.

\begin{tabular}{|c|c|c|c|c|c|c|c|}
\hline Run Pt. & $\begin{array}{l}\text { Pressure } \\
\text { MPa }\end{array}$ & $\begin{array}{c}\text { Temperature } \\
\mathrm{K}\end{array}$ & $\begin{array}{l}\text { Density } \\
\text { mol/L }\end{array}$ & $\begin{array}{l}\text { Power } \\
\text { W/m }\end{array}$ & $\begin{array}{l}\text { Thermal } \\
\text { Conductivity } \\
\text { W/m.K }\end{array}$ & STAT & $\begin{array}{c}\text { Conductivity } \\
\text { with } \mathrm{T}=300.65 \mathrm{~K} \\
\mathrm{~W} / \mathrm{m} \cdot \mathrm{K}\end{array}$ \\
\hline 9001 & 63.980 & 306.154 & 19.6780 & .36457 & .18386 & .022 & .18193 \\
\hline 9002 & 63.978 & 306.459 & 19.6629 & .46029 & .18445 & .014 & .18242 \\
\hline 9003 & 63.978 & 306.788 & 19.6469 & .56726 & .18336 & .011 & .18121 \\
\hline 9004 & 63.979 & 307.287 & 19.6229 & .68489 & .18479 & .009 & .18247 \\
\hline 9005 & 63.979 & 307.741 & 19.6010 & .81392 & .18424 & .006 & .18176 \\
\hline 9006 & 63.979 & 308.241 & 19.5769 & .95386 & .18427 & .005 & .18161 \\
\hline 9007 & 61.905 & 306.849 & 19.1335 & .56688 & .18268 & .010 & .18051 \\
\hline 9008 & 61.905 & 308.397 & 19.0601 & .95337 & .18285 & .005 & .18014 \\
\hline 9009 & 59.692 & 306.827 & 18.5826 & .56708 & .18132 & .010 & .17916 \\
\hline 9010 & 59.693 & 307.794 & 18.5380 & .81386 & .18250 & .007 & .18000 \\
\hline 9011 & 57.621 & 306.382 & 18.0798 & .46038 & . 17957 & .014 & .17756 \\
\hline 9012 & 57.622 & 307.822 & 18.0144 & .81384 & .18141 & .006 & .17890 \\
\hline 9013 & 55.588 & 306.292 & 17.5633 & .46046 & .17811 & .015 & .17614 \\
\hline 9014 & 55.588 & 307.767 & 17.4977 & .81391 & .17947 & .006 & .17698 \\
\hline 9015 & 53.338 & 306.324 & 16.9781 & .46030 & .17822 & .015 & .17623 \\
\hline 9016 & 53.338 & 307.769 & 16.9154 & .81397 & .17892 & .007 & .17643 \\
\hline 9017 & 51.292 & 306.429 & 16.4358 & .46023 & .17730 & .015 & .17528 \\
\hline 9018 & 51.293 & 307.763 & 16.3793 & .81388 & .17749 & .006 & .17500 \\
\hline 9019 & 49.069 & 306.377 & 15.8453 & .46028 & .17662 & .014 & .17462 \\
\hline 9020 & 49.070 & 307.784 & 15.7876 & .81385 & .17682 & .006 & .17432 \\
\hline 9021 & 46.963 & 306.311 & 15.2786 & .46031 & .17652 & .015 & .17454 \\
\hline 9022 & 46.964 & 307.749 & 15.2211 & .81389 & .17577 & .006 & .17329 \\
\hline 9023 & 44.676 & 306.361 & 14.6495 & .46023 & .17437 & .013 & .17237 \\
\hline 9024 & 44.678 & 307.731 & 14.5966 & .81401 & .17554 & .006 & .17306 \\
\hline 9025 & 42.449 & 306.396 & 14.0279 & .46025 & .17243 & .013 & .17042 \\
\hline 9026 & 42.449 & 307.874 & 13.9726 & .81371 & .17387 & .006 & .17134 \\
\hline 9027 & 40.222 & 306.328 & 13.4010 & .46013 & .17191 & .014 & .16992 \\
\hline 9028 & 40.222 & 307.816 & 13.3472 & .81378 & .17336 & .006 & .17085 \\
\hline 9029 & 38.053 & 306.321 & 12.7787 & .46027 & .17121 & .013 & .16923 \\
\hline 9030 & 38.053 & 307.861 & 12.7251 & .81376 & .17216 & .006 & .16964 \\
\hline 9031 & 35.850 & 306.292 & 12.1378 & .46029 & .17026 & .014 & .16829 \\
\hline 9032 & 35.851 & 307.886 & 12.0847 & .81381 & .17134 & .006 & .16881 \\
\hline 9033 & 33.592 & 305.206 & 11.5040 & .20675 & .16850 & .042 & .16691 \\
\hline 9034 & 33.592 & 305.508 & 11.4943 & .28015 & .16954 & .029 & .16784 \\
\hline 9035 & 33.592 & 305.853 & 11.4833 & .36455 & .16908 & .020 & .16726 \\
\hline 9036 & 33.592 & 306.306 & 11.4688 & .46028 & .16863 & .014 & .16665 \\
\hline 9037 & 33.593 & 306.741 & 11.4552 & .56704 & .17039 & .010 & .16826 \\
\hline 9038 & 33.594 & 307.256 & 11.4389 & .68485 & .16933 & .008 & .16702 \\
\hline 9039 & 33.594 & 307.857 & 11.4198 & .81389 & .17057 & .006 & .16805 \\
\hline 9040 & 33.594 & 305.799 & 11.4856 & .36407 & .16952 & .020 & .16772 \\
\hline 9041 & 33.594 & 306.338 & 11.4684 & .45965 & .16955 & .013 & .16756 \\
\hline 9042 & 33.595 & 306.824 & 11.4531 & .56620 & .16952 & .011 & .16736 \\
\hline 9043 & 33.595 & 307.313 & 11.4375 & .68391 & .16982 & .008 & .16749 \\
\hline 9044 & 33.595 & 307.790 & 11.4223 & .81285 & .17030 & .006 & .16780 \\
\hline 9045 & 33.595 & 308.438 & 11.4018 & .95255 & .17128 & .005 & .16855 \\
\hline 9045 & 31.497 & 306.173 & 10.8425 & .46033 & .16840 & .013 & .16647 \\
\hline 9046 & 31.497 & 307.807 & 10.7931 & .81402 & .16980 & .006 & .16730 \\
\hline 9047 & 28.968 & 306.381 & 10.0629 & .46036 & .16811 & .013 & .16610 \\
\hline 9048 & 28.968 & 307.941 & 10.0184 & .81396 & .16769 & .006 & .16514 \\
\hline 9049 & 26.634 & 306.344 & 9.3369 & .46035 & .16695 & .014 & .16496 \\
\hline 9050 & 26.634 & 307.965 & 9.2936 & .81397 & .16735 & .005 & .16479 \\
\hline 9051 & 24.532 & 306.354 & 8.6709 & .46038 & .16588 & .014 & .16388 \\
\hline 9052 & 24.532 & 307.963 & 8.6306 & .81417 & .16621 & .006 & .16365 \\
\hline 9053 & 22.396 & 306.379 & 7.9829 & .46046 & .16482 & .013 & .16281 \\
\hline 9054 & 22.395 & 308.019 & 7.9445 & .81418 & .16552 & .006 & .16294 \\
\hline 9055 & 20.255 & 306.511 & 7.2793 & .46102 & .16399 & .013 & .16194 \\
\hline 9056 & 20.255 & 308.186 & 7.2434 & .81536 & .16490 & .006 & .16226 \\
\hline 9057 & 17.991 & 306.347 & 6.5288 & .46009 & .16298 & .014 & .16099 \\
\hline 9058 & 17.913 & 308.066 & 6.4692 & .81378 & .16397 & .006 & .16137 \\
\hline 9059 & 15.627 & 305.967 & 5.7333 & .36458 & .16262 & .018 & .16076 \\
\hline 9060 & 15.627 & 306.425 & 5.7254 & .46017 & .16148 & .012 & .15946 \\
\hline 9061 & 15.626 & 306.897 & 5.7170 & .56700 & .16220 & .010 & .16001 \\
\hline 9062 & 15.626 & 307.578 & 5.7052 & .68465 & .16218 & .008 & .15976 \\
\hline 9063 & 15.626 & 308.170 & 5.6951 & .81363 & .16305 & .006 & .16042 \\
\hline 9064 & 13.436 & 305.988 & 4.9748 & .36453 & .16032 & .019 & .15841 \\
\hline 9065 & 13.436 & 307.519 & 4.9516 & .68483 & .16199 & .007 & .15959 \\
\hline
\end{tabular}


Table 4. (Continued)

\begin{tabular}{|c|c|c|c|c|c|c|c|}
\hline Run Pt. & $\begin{array}{l}\text { Pressure } \\
\mathrm{MPa}\end{array}$ & $\begin{array}{c}\text { Temperature } \\
\text { K }\end{array}$ & $\begin{array}{c}\text { Density } \\
\text { mol/L }\end{array}$ & $\begin{array}{l}\text { Power } \\
\mathrm{W} / \mathrm{m}\end{array}$ & $\begin{array}{l}\text { Thermal } \\
\text { Conductivity } \\
\text { W/m॰K }\end{array}$ & STAT & $\begin{array}{c}\text { Conductivity } \\
\text { with } \mathrm{T}=300.65 \mathrm{~K} \\
\mathrm{~W} / \mathrm{m} \cdot \mathrm{K}\end{array}$ \\
\hline $\begin{array}{l}9066 \\
9067 \\
9068 \\
9069 \\
9070 \\
9071 \\
9072 \\
9073 \\
9074 \\
9075 \\
9076\end{array}$ & $\begin{array}{r}11.253 \\
11.253 \\
9.013 \\
9.013 \\
6.648 \\
6.648 \\
4.466 \\
4.466 \\
2.419 \\
2.418 \\
.415\end{array}$ & $\begin{array}{l}305.990 \\
307.633 \\
305.969 \\
307.727 \\
305.860 \\
307.452 \\
305.982 \\
307.438 \\
306.028 \\
307.670 \\
306.143\end{array}$ & $\begin{array}{r}4.2056 \\
4.1844 \\
3.4013 \\
3.3827 \\
2.5362 \\
2.5232 \\
1.7199 \\
1.7119 \\
.9401 \\
.9349 \\
.1627\end{array}$ & $\begin{array}{l}.36453 \\
.68454 \\
.36451 \\
.68445 \\
.36460 \\
.68476 \\
.36440 \\
.68485 \\
.36441 \\
.68458 \\
.36423\end{array}$ & $\begin{array}{l}.16059 \\
.16030 \\
.15889 \\
.15957 \\
.15773 \\
.15851 \\
.15684 \\
.15705 \\
.15672 \\
.15595 \\
.15477\end{array}$ & $\begin{array}{l}.019 \\
.008 \\
.019 \\
.007 \\
.012 \\
.006 \\
.016 \\
.008 \\
.023 \\
.012 \\
.222\end{array}$ & $\begin{array}{l}.15872 \\
.15786 \\
.15703 \\
.15709 \\
.15591 \\
.15613 \\
.15497 \\
.15467 \\
.15484 \\
.15349 \\
.15285\end{array}$ \\
\hline
\end{tabular}

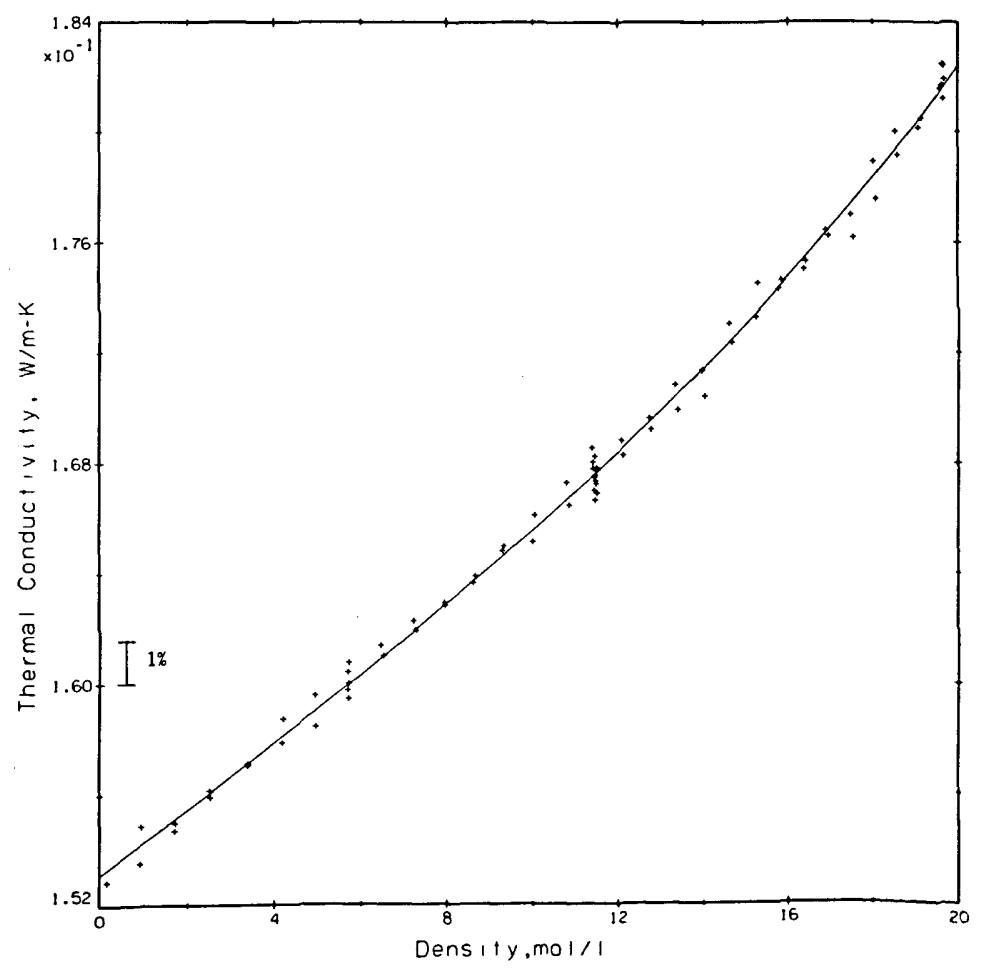

FIGURE 13. Helium measurements shifted to $300.65 \mathrm{~K}$ with curve fit, eq (9). 


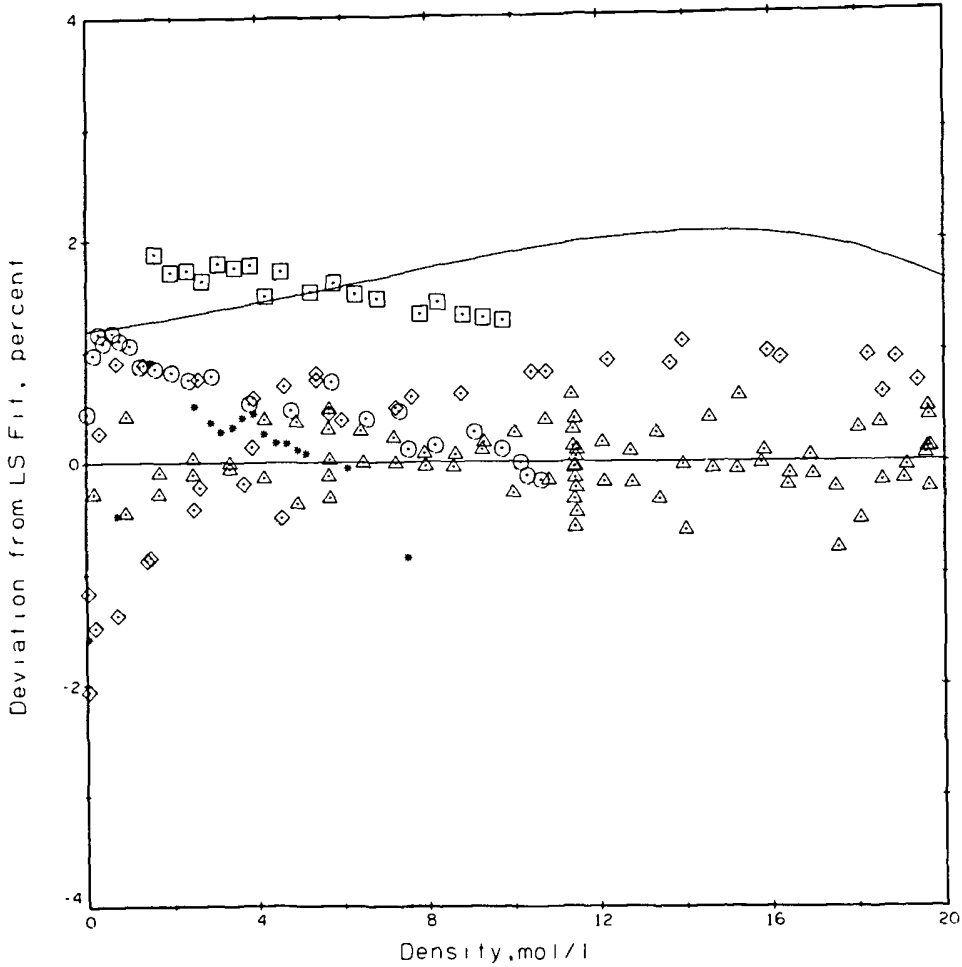

Ficure 14. Comparison of the present results with those of others for helium at $300.65 \mathrm{~K}$. Base line eq (9), $\triangle$ this paper, $\square$ Kestin, et al. [7], $\diamond$ Le Neindre, et al. [34], * Johannin, et al. [35], $O$ Ho and Leidenfront [36], - McCarty [37] correlation.

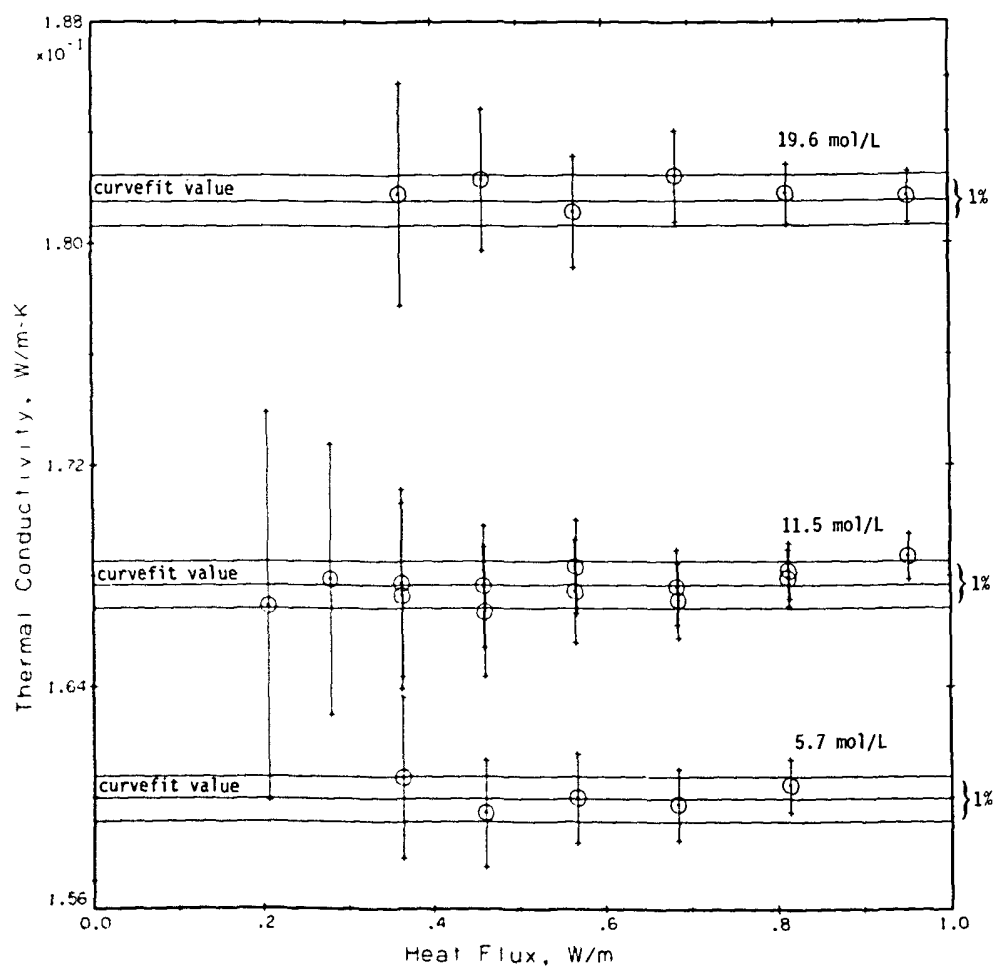

Figure 15. Measured thermal conductivity as a function of the applied power. Apparatus test with helium gas. 
measurements made the same day with the full bridge. The apparent conductivities for the single wires increase above those of the full bridge as follows

$\begin{array}{ll}\text { full bridge } & 1.000 \\ \text { long hot wire only } & 1.048 \\ \text { short hot wire only } & 1.083 .\end{array}$

Measurements of this type show the relative effect of the end corrections which would be required for the single wire, but which are presumed to be off setting in the bridge circuit.

\section{Errors}

Precision, reproducibility, internal consistency, and accuracy are discussed here.

Precision. The measurement variation in the voltages across the Wheatstone bridge is $\pm 28 \mu \mathrm{V}$ which corresponds to about $25 \mathrm{mK}$. The effective errors in the experimental $\Delta T$ values are 6 percent for the very small power levels, i.e., a final $\Delta T$ of about $0.5 \mathrm{~K}$, to 0.4 percent for a final $\Delta T$ of about $6 \mathrm{~K}$. An example of the distribution of the experimental $\Delta T^{\prime} \mathrm{s}$ about the calculated straight line was shown in figure $8 \mathrm{~b}$. The regression program accounts for the spread in measurements by assigning a variance to the coefficients of the calculated straight line. The value STAT as printed in tables 3 and 4 is the fractional error in the slope of the straight line obtained from the variance in the slope $(2 \sigma)$ divided by by the slope itself. The value STAT is the primary measure of the experimental precision because other contributions such as an error in $q$ are quite negligible. For final $\Delta T$ values of $3.5 \mathrm{~K}$ or more which includes about 70 percent of all measurements made to date the nominal precision $(2 \sigma)$ is 0.6 percent or slightly less.

Reproducibility was tested by measuring (a) repeatedly the same point at the same fluid conditions on a given day, (b) by measuring similar points at different power levels, and (c) by repeating different isotherms at different times some months apart. Examples of (a) are found in table 3, examples of (b) are given in the sections on nitrogen and helium. For (c), isotherms at $160 \mathrm{~K}, 200 \mathrm{~K}$, and $240 \mathrm{~K}$ were repeated during the measurements on oxygen [26].

Internal consistency. When measurements are made over a large portion of the thermal conductivity surface, and if an analytical function is used to represent the surface, then it becomes possible to check the internal consistency of the set of measurements by intercomparing the deviations and deviation patterns for the various isotherms. Such checks are possible for both propane [27] and oxygen [26]. In pro- pane seven different liquid isotherms can be represented with an overall deviation of 1.2 percent $(2 \sigma)$. For oxygen, 13 isotherms from the surface which includes gas, liquid, subcritical vapor and the near critical region for an average deviation of 1.6 percent.

Accuracy. The accuracy of the measurement can in principle be established from the measurements and certain theoretical considerations, i.e., for the rare gases the Eucken factor [7]. For argon [30] the 0.3 percent obtained in the low density extrapolation was considered a fortunate coincidence and an overall accuracy of \pm 1 percent was claimed. For the results on helium in table 4 the low density extrapolation yields a result which is 1.8 percent low. Accuracy can also be estimated by comparison to the results of others. For the present apparatus these intercomparisons cover a wide range of fluids, and a wide range of pressures, densities and temperatures. Summarized these comparisons are:

Nitrogen: this apparatus is 1.3 to 2.3 percent lower than other authors $[31,32,33]$.

Helium: this apparatus is 1 . to 1.8 percent lower than other authors $[7,34,35,36,37]$.

Argon: this apparatus is 1 . percent lower than other authors [30].

Oxygen: this apparatus is 1-2 percent lower than other authors [26].

Propane: this apparatus is higher at some densities, lower at other densities when compared to other authors [27].

Hydrogen: this apparatus is 1.5 percent lower than other authors [39].

\section{Summary}

A new transient hot wire thermal conductivity apparatus for fluids has been developed. It differs from some of the other transient hot wire systems in that it uses compensating wires in a Wheatstone bridge arrangement. It differs from those transient hot wire systems that use a bridge in that the voltages developed across the bridge are measured directly. The apparatus is a very rapid measuring device. Sixty points, a full pseudo-isotherm, are possible in a day. The system is capable of measuring a wide range of fluid temperatures, densities, and pressures. Fluid states, such as dilute gas, dense gas, the near critical states, vapor at tem. peratures below critical, compressed liquid states, and metastable liquid states at densities below saturation, are accessible for many liquefied gases. A wide variety of simple fluids has been measured in the system so far. It appears that the precision of the new system is on the order of 0.6 percent while its accuracy is close to 1.5 percent. 


\section{References}

[1] Pittman, J. F. T. Fluid thermal conductivity determination by the transient line source method. Thesis. University of London; London; 1968.

[2] Haarman, J. W. Thesis. Technische Hogeschool; Delft; 1969.

[3] Mani, N. Precise determination of the thermal conductivity of fluids using absolute transient hot-wire technique. Thesis. University of Calgary. Calgary, Alberta, Canada. 1971 Aygust.

[4] de Groot, J. J.; Kestin, J.; Sookiazian, H. Instrument to measure the thermal conductivity of gases. Physica. 75: 454-482; 1974.

[5] Healy, J. J.; de Groot, J. J.; Kestin, J. The theory of the transient hotwire method for measuring thermal conductivity. Physica $82 \mathrm{C}(2)$; 392-408; 1976 April.

[6] de Groot, J. J.; Kestin, J.; Sookiazian, H. The thermal conductivity of four monatomic gases as a function of density near room temperature. Physica. 92A: 117-144; 1978.

[7] Kestin, J.; Paul, R.; Clifford, A. A.; Wakeham, W. A. Absolute determination of the thermal conductivity of the noble gases at room temperature up to $35 \mathrm{MPa}$. Physica 100A(2): 349-369; 1980 February.

[8] Kestin, J.; Wakeham, W. A. A contribution to the theory of the transient hot-wire technique for thermal conductivity measurements. Physica. 92A(1 and 2): 102-116; 1978 June.

[9] Clifford, A. A.; Kestin, J.; Wakeham, W. A. A further contribution to the theory of the transient hot-wire technique for thermal conductivity measurements. Physica. 100A(2): 370-374; 1980 February.

[10] Assael, M. J.; Dix, M.; Lucas, A.; Wakeham, W. A. Absolute determination of the thermal conductivity of the noble gases and two of their binary mixtures. J. Chem. Soc., Faraday Trans. 77(1): 439-464; 1981.

[11] Menashe, J.; Wakeham, W. A. Absolute measurements of the thermal conductivity of liquids of pressures up to $500 \mathrm{MPa}$. to be published, Physica.

[12] de Castro, C. A. Nieto; Calado, J. C. G.; Wakeham, W. A.; Dix, M. An apparatus to measure the thermal conductivity of liquids. Journal of Physics E: Scient. Inst. 9: 1073-1080; 1976.

[13] de Castro, C. A. Nieto; Calado, J. C. G.; Wakeham, W. A. Absolute measurements of the thermal conductivity of liquids using a transient hot-wire technique. Cezarilyan, A. ed. Proceedings of the seventh symposium on thermophysical properties; 1977 May 10-12; Gaithersburg, Maryland; New York; ASME; 1977; 730-738.

[14] Carslaw, H. S.; Jaeger, J. C. Conduction of heat in solids. 2nd Ed. 0xford: University Press; 1959. $510 \mathrm{p}$.

[15] Riddle, J. L.; Furukawa, G. T.; Plumb, H. H. Platinum Resistance Thermometry. Nat. Bur. Stand. (U.S.) Monogr. 126; 1973 April. 129 p.

[16] Lyman, T., ed. Metals Handbook. 8th Ed. Vol 1. Properties and Selection of Metals. American Society for Metals. Metals Park, Ohio; 1969 September. $1300 \mathrm{p}$.

[17] Younglove, B. A. Speed of sound in fluid parahydrogen. J. Acoust. Soc. Am. 38(3): 433-438; 1965 September.

[18] Diller, D. E. Measurements of the viscosity of parahydrogen. J. Chem. Phys. 42(6): 2089-2100; 1965 March 15.

[19] Weber, L. A. Density and compressibility of oxygen in the critical region. Phys. Rev. A 246): 2379-2388; 1970 December.

[20] Haynes, W. M.; Hiza, M. J.; Frederick, N. V. Magnetic suspension densimeter for measurements on fluids of cryogenic interest. Rev Sci. Instrum. 47(10): 1237-1250; 1976 October.

[21] Straty, G. C.; Younglove, B. A. A fluorine compatible low temperature electrical feed through. Rev. Sci. Instrum. 43(1): 156-157; 1972 January.
[22] Key, C. F. Compatibility of materials with liquid oxygen, III. National Aeronautics and Space Administration, Marshall Space Flight Center, Huntsville, Ala; Tech. Memo X67-10596; 1966 November.

[23] Bankaitis, H.; Schueller, C. F. ASRDI Oxygen technology survey Volume II: cleaning requirements, procedures, and verification techniques. National Aeronautics and Space Administration Special Publication SP-3072; 1972. 76 p.

[24] Goodwin, R. D. Apparatus for determination of pressure-density-temperature relations and specific heats of hydrogen to 350 atmospheres at temperatures above $14 \mathrm{~K}$. J. Res. Nat. Bur. Stand. (U.S.) 65C(4): 231-243; 1961 October-December.

[25] Goodwin, R. D. An improved DC power regulator. Timmerhaus, K. D., ed. Advances in Cryogenic Engineering. Proceedings of the 1959 Cryogenic Engineering Conference. Plenum Press Inc., New York; 1960. 577-579.

[26] Roder, H. M. The thermal conductivity of oxygen. J. Res. Nat. Bur. Stand. (U.S.). to be published.

[27] Roder, H. M.; de Castro, C. A. N. Thermal conductivity of liquid pro* pane. Submitted to J. Chem. Engr. Data.

[28] Hall, L. A. Survey of electrical resistivity measurements on 16 pure metals in the temperature range 0 to $273 \mathrm{~K}$. Nat. Bur. Stand. (U.S.) Tech. Note 365; 1968 February. 111 p.

[29] de Castro, C. A. Nieto; Wakeham, W. A. Experimental aspects of the transient hot-wire technique for thermal conductivity measurements. Mirkovich, V. V. ed. Thermal conductivity 15. 1977 August 24-26; Ottawa, Ontario, Canada; New York; Plenum Publ. Corp.; 1978; 235-243.

[30] de Castro, C. A. N.; Roder, H. M. Absolute determination of the thermal conductivity of argon at room temperature and pressures up to $68 \mathrm{MPa}$. J. Res. Nat. Bur. Stand. (U.S.). 86(3): 293-307; 1981 MayJune.

[31] Clifford, A. A.; Kestin, J.; Wakeham, W. A. Thermal conductivity of $\mathrm{N}_{2}, \mathrm{CH}_{4}$, and $\mathrm{CO}_{2}$ at room temperature and at pressures up to 35 MPa. Physica. 97A(2): 287-295; 1979 July.

[32] Assael, M. J.; Wakeham, W. A. Thermal conductivity of four polyatomic gases. J. Chem. Soc., Faraday Trans. 77(1): 697-707; 1981.

[33] Hanley, H. J. M.; McCarty, R. D.; Haynes, W. M. The viscosity and thermal conductivity for dense gaseous and liquid argon, krypton, xenon, nitrogen and oxygen. J. Phys. Chem. Ref. Data 3(4): 979-1017; 1974.

[34] Le Neindre, B.; Bury, P.; Tufeu, R.; Johannin, P.; Vodar, B. Recent developments at Bellevue on thermal conductivity measurements of compressed gases. Flynn, D. A.; Peavy, B. A., Jr. ed. Thermal conductivity; Proceedings of the seventh conference; 1967 November 13-16; Gaithersburg, Maryland. Nat. Bur. Stand. (U.S.) Spec. Publ. 302; 1968 September. 579-593.

[35] Johannin, P.; Wilson, M.; Vodar, B. Heat conductivity of helium at elevated temperatures. Masi, J. F.; Tsai, D. H. ed. Progress in International Research on Thermodynamic and Transport Properties. Academic Press, New York. 1962. 418-433.

[36] Ho, C. W.; Leidenfrost, W. Precise determination of the thermal conductivity of helium gas at high pressures and moderate temperatures. Grigull, U.; Hahnl, E. eds. Progress in Heat and Mass Transfer. Pergamon Press, Oxford; 1969. 55-98.

[37] McCarty, R. B. Thermophysical properties of helium-4 from 2 to 1500 $\mathrm{K}$ with pressures to 1000 atmospheres. Nat. Bur. Stand. (U.S.) Tech. Note 631; 1972 November. 161 p.

[38] Roder, H. M.; Diller, D. E. Thermal conductivity of gaseous and liquid hydrogen. J. Chem. Phys. 52(11): 5928-5949; 1970 June 1.

[39] Roder, H. M. Thermal conductivity of normal hydrogen. Presented at the 17th International Thermal Conductivity Conference. Gaithersburg, Maryland; 1981 June 15-18. 
10 FEY FFOGFAM TEST, FESULTS ONTO TAFE, FEUTSER 20 TIEC 79

20 DIM AL:255] B BL255]

30 LEET I. $2=250$

40 REM WHEATSTONE BALANCE

SO REM HOTWTFE STME ONLY

60 FFTNT " DITAL TN VOL TS SHOUL BE O.1"

70 FFINT "TOTAL R3" "TORAL.. RA", "R3 FOT SET", "FA FOT SET"

75 CALL. $9,3,0$

80 CALL. $9,1.6$

$90 \mathrm{FOK}, \mathrm{O}=0 \mathrm{TO} 7$

1.00 LET $\cup[]=$.

105 CALL $5,1,128,1,1,4$

110 FOF $x=1$ TO 250

120 CALLL OARTI

$150 \quad$ LET $U[].]=U[\because]+A[T]$

160 NEXT I

170 LET UL.J]=UR.J I/250

1.80 NEXT J

190 CALL. 9, 9. 0

210 LEET $C=U[0.1 / 100$

220 FOF $\mathrm{I}=1$ rO 7

230 LET FET] TEVTI

240 NEXY T.

250 LET R3 $3=F[1]+F[2]+F[3]$

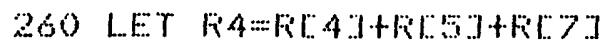

300 FFINT R3, FA, RIDT, FIST

310 FFINT "GO AGAIN ?"

320 TNFUT バ!

330 TF KII= O GOTO 80

340 REM FULL. BRTIIGE

350 LET U[G] $=0$

360 CALL. 993,6

370 CALI. $9,1,6$

380 CALL $5,1,1024,6,6,4$

390 FOF $\mathrm{I}=1$ TO 250

100 CALL. G,ALTI

$410 \quad$ LET U[:G] $U[6]+A[T]$

420 NEXT I

430 LET U1:6]=U56..2/250

440 CALL $9,1,0$

450 CALL $9.3,0$

A6O FRTNT "WHEATSTONE BALANCE = "U[6]," GO AGATN ?

470 INFUT KKL

480 THE KIL 0 BOro 350

490 BEM INTTRAL... CONOTTRONS

500 LEV $r I=0$

510 LEV T2:-296.06+(Fi.37-90.58)/.33

520 LET A[ O] $=0[6]$

530 FFITIT

540 FVINT "TTME-Z" "TEMF-Z", "RZZ-Z", "FA-Z", "U OFFS-Z"

550 FFINT T1, T2, F[3], F[A], A[ O] 


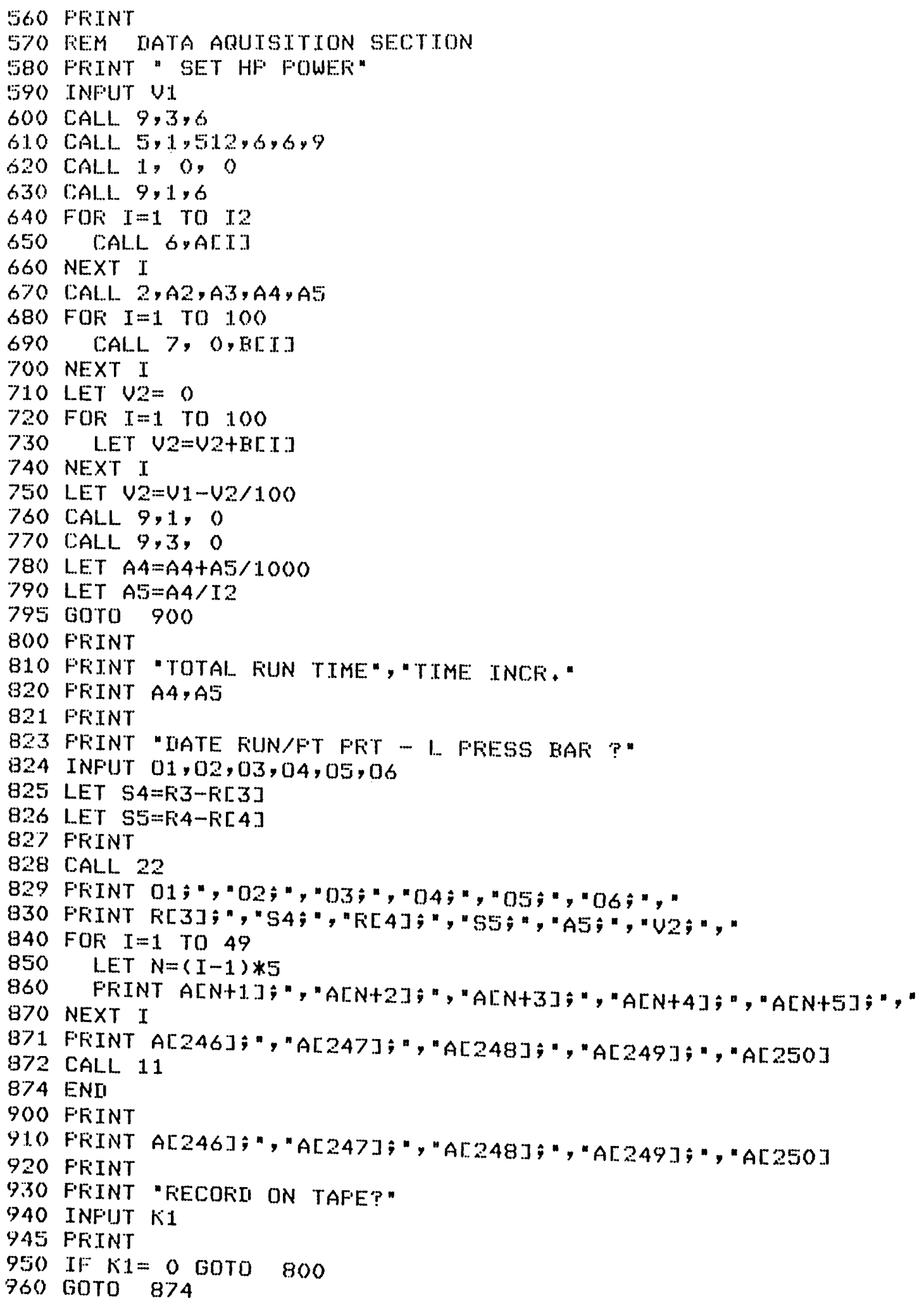


Appendix II. Data for Point 9044, Helium Gas

$800116,9044,57515.7, .7,4710.1,626.7$, $93.3094,6.65579,46.7144,53.4657, .00302,6.07389$, $-7.06954 \mathrm{E}-4,5.15612 \mathrm{E}-4,1.07951 \mathrm{E}-3,1.40795 \mathrm{E}-3,1.68155 \mathrm{E}-3$, $1.84488 \mathrm{E}-3,2.00463 \mathrm{E}-3,2.1614 \mathrm{E}-3,2.2985 \mathrm{E}-3,2.43559 \mathrm{E}-3$, $2.47911 \mathrm{E}-3,2.55064 \mathrm{E}-3,2.65734 \mathrm{E}-3,2.74794 \mathrm{E}-3,2.79682 \mathrm{E}-3$, $2.86418 \mathrm{E}-3,2.91842 \mathrm{E}-3,2.96074 \mathrm{E}-3,3.01201 \mathrm{E}-3,3.07459 \mathrm{E}-3$, $3.16818 \mathrm{E}-3,3.16639 \mathrm{E}-3,3.16878 \mathrm{E}-3,3.23256 \mathrm{E}-3,3.31303 \mathrm{E}-3$, $3.32376 \mathrm{E}-3,3.35952 \mathrm{E}-3,3.38992 \mathrm{E}-3,3.44953 \mathrm{E}-3,3.45609 \mathrm{E}-3$, $3.48649 \mathrm{E}-3,3.55206 \mathrm{E}-3,3.56219 \mathrm{E}-3,3.55087 \mathrm{E}-3,3.58603 \mathrm{E}-3$, $3.64683 \mathrm{E}-3,3.6671 \mathrm{E}-3,3.6975 \mathrm{E}-3,3.69869 \mathrm{E}-3,3.73088 \mathrm{E}-3$,

$3.75174 \mathrm{E}-3,3.77559 \mathrm{E}-3,3.84712 \mathrm{E}-3,3.82506 \mathrm{E}-3,3.82149 \mathrm{E}-3$, $3.84414 \mathrm{E}-3,3.90017 \mathrm{E}-3,3.90673 \mathrm{E}-3,3.94309 \mathrm{E}-3,3.94249 \mathrm{E}-3$, $3.95084 \mathrm{E}-3,3.96335 \mathrm{E}-3,3.99375 \mathrm{E}-3,4.04263 \mathrm{E}-3,4.03667 \mathrm{E}-3$, 4.01819E-3, 4.02296E-3, 4.09568E-3, 4.10284E-3, 4.12549E-3, $4.11595 \mathrm{E}-3,4.13562 \mathrm{E}-3,4.14874 \mathrm{E}-3,4.1696 \mathrm{E}-3,4.19344 \mathrm{E}-3$, 4.22086E-3, 4.20119E-3, 4.19881E-3, 4.24292E-3, 4.26914E-3, $4.29835 \mathrm{E}-3,4.27332 \mathrm{E}-3,4.27391 \mathrm{E}-3,4.29716 \mathrm{E}-3,4.32518 \mathrm{E}-3$, 4.32994E-3, 4.35677E-3, 4.34485E-3, 4.36571E-3, 4.37644E-3, $4.39194 \mathrm{E}-3,4.42115 \mathrm{E}-3,4.4128 \mathrm{E}-3,4.40505 \mathrm{E}-3,4.41161 \mathrm{E}-3$, 4.44678E-3, 4.45691E-3, 4.48672E-3, 4.46406E-3, 4.47062E-3, $4.49268 \mathrm{E}-3,4.51115 \mathrm{E}-3,4.5499 \mathrm{E}-3,4.51712 \mathrm{E}-3,4.52248 \mathrm{E}-3$, 4.52904E-3, 4.55586E-3, 4.55884E-3, 4.60414E-3, 4.58268E-3, $4.56361 \mathrm{E}-3,4.5797 \mathrm{E}-3,4.61964 \mathrm{E}-3,4.64229 \mathrm{E}-3,4.62203 \mathrm{E}-3$, $4.6107 \mathrm{E}-3,4.62262 \mathrm{E}-3,4.66494 \mathrm{E}-3,4.66316 \mathrm{E}-3,4.69475 \mathrm{E}-3$, $4.68461 \mathrm{E}-3,4.67269 \mathrm{E}-3,4.68163 \mathrm{E}-3,4.72336 \mathrm{E}-3,4.72813 \mathrm{E}-3$, $4.72753 \mathrm{E}-3,4.70727 \mathrm{E}-3,4.71203 \mathrm{E}-3,4.74601 \mathrm{E}-3,4.75555 \mathrm{E}-3$, $4.78476 \mathrm{E}-3,4.76211 \mathrm{E}-3,4.75078 \mathrm{E}-3,4.76866 \mathrm{E}-3,4.79847 \mathrm{E}-3$, 4.79727E-3, 4.81277E-3, 4.80383E-3, 4.82589E-3, 4.82469E-3, $4.83006 \mathrm{E}-3,4.8688 \mathrm{E}-3,4.84973 \mathrm{E}-3,4.82767 \mathrm{E}-3,4.83125 \mathrm{E}-3$, 4.87357E-3, 4.87834E-3, 4.89265E-3, 4.87476E-3, 4.88669E-3, $4.89622 \mathrm{E}-3,4.90934 \mathrm{E}-3,4.94451 \mathrm{E}-3,4.91828 \mathrm{E}-3,4.90993 \mathrm{E}-3$, $4.90874 \mathrm{E}-3,4.93378 \mathrm{E}-3,4.94272 \mathrm{E}-3,4.97729 \mathrm{E}-3,4.9457 \mathrm{E}-3$, 4.93199E-3, 4.95404E-3, 4.98444E-3, 4.99637E-3, 4.97789E-3, $4.97371 \mathrm{E}-3,4.9761 \mathrm{E}-3,5.0071 \mathrm{E}-3,5.0071 \mathrm{E}-3,5.03988 \mathrm{E}-3$, $5.02379 \mathrm{E}-3,5.00352 \mathrm{E}-3,5.01604 \mathrm{E}-3,5.05776 \mathrm{E}-3,5.05538 \mathrm{E}-3$, $5.0524 \mathrm{E}-3,5.0369 \mathrm{E}-3,5.03392 \mathrm{E}-3,5.0673 \mathrm{E}-3,5.07624 \mathrm{E}-3$, $5.10724 E-3,5.07743 E-3,5.0673 E-3,5.08339 E-3,5.10903 E-3$, $5.09889 \mathrm{E}-3,5.11618 \mathrm{E}-3,5.10187 \mathrm{E}-3,5.12333 \mathrm{E}-3,5.1126 \mathrm{E}-3$, $5.12452 \mathrm{E}-3,5.16387 \mathrm{E}-3,5.14062 \mathrm{E}-3,5.11618 \mathrm{E}-3,5.1275 \mathrm{E}-3$, $5.17281 \mathrm{E}-3,5.16565 \mathrm{E}-3,5.17817 \mathrm{E}-3,5.15016 \mathrm{E}-3,5.16983 \mathrm{E}-3$, $5.17221 \mathrm{E}-3,5.17817 \mathrm{E}-3,5.22169 \mathrm{E}-3,5.19605 \mathrm{E}-3, .005174$, $5.1734 \mathrm{E}-3,5.20678 \mathrm{E}-3,5.21632 \mathrm{E}-3,5.23599 \mathrm{E}-3,5.20976 \mathrm{E}-3$, $5.19725 \mathrm{E}-3,5.21871 \mathrm{E}-3,5.23838 \mathrm{E}-3,5.25685 \mathrm{E}-3,5.23838 \mathrm{E}-3$, $5.23063 \mathrm{E}-3,5.22407 \mathrm{E}-3,5.26222 \mathrm{E}-3,5.25924 \mathrm{E}-3,5.28725 \mathrm{E}-3$, $5.26639 \mathrm{E}-3,5.2503 \mathrm{E}-3,5.25745 \mathrm{E}-3,5.28368 \mathrm{E}-3,5.29798 \mathrm{E}-3$, $5.29321 \mathrm{E}-3,5.26937 \mathrm{E}-3,5.27176 \mathrm{E}-3,5.31229 \mathrm{E}-3,5.31229 \mathrm{E}-3$, $5.33434 \mathrm{E}-3,5.31169 \mathrm{E}-3,5.30514 \mathrm{E}-3,5.30514 \mathrm{E}-3,5.32838 \mathrm{E}-3$, $5.32242 \mathrm{E}-3,5.34686 \mathrm{E}-3,5.32361 \mathrm{E}-3,5.3409 \mathrm{E}-3,5.33673 \mathrm{E}-3$, $.005357,5.38263 \mathrm{E}-3,5.35461 \mathrm{E}-3,5.33375 \mathrm{E}-3,5.34984 \mathrm{E}-3$, $5.38084 \mathrm{E}-3,5.37607 \mathrm{E}-3,5.39097 \mathrm{E}-3,5.37667 \mathrm{E}-3,5.38322 \mathrm{E}-3$, $5.3862 \mathrm{E}-3,5.39157 \mathrm{E}-3,5.43866 \mathrm{E}-3,5.40766 \mathrm{E}-3,5.38322 \mathrm{E}-3$, $5.37965 \mathrm{E}-3,5.41243 \mathrm{E}-3,5.42137 \mathrm{E}-3,5.43926 \mathrm{E}-3,5.41005 \mathrm{E}-3$ 
Appendix III. The Helium Data Reduction Program PROGRAM HE(INPUT, OUTPUT, TAPE1)

C HELIUM COND. DATA REDUCTION, FINAL DR/DT, REVISED 9 MAR 81

C FOR LS ALONG THE DATA: CALL LS

C FOR PLOT: $\operatorname{CALL} \operatorname{PLOT}(G(1), G(2))$

DIMENSION DTR(250), DTC(250), TLOG(250), VOF(250)

DIMENSION $F(40), G(10)$

DIMENSION BFY(5), GNU(5),DT1(250),DT2(250), DT3(250), DT4(250),

1 DT5(250), $\operatorname{VOLT}(250), \mathrm{QI}(250)$

DIMENSION ITITLE(13), NAME(8)

COMMON/DDC/LU, LUC, IFL

COMMON/8/ IN,IK, P, T,DEN, E,H,S, CV , CP, CSAT, W, WK

COMMON/LSS/DTR, DTC, TLOG, Q, PRTT

COMMON /FITT/ F,Y,NFUN

COMMON/DATATC/R1, R2, R3Z, R4Z, R3B , R4B , PRESS ,TEMP , VOF , TINC

DATA BFY $/ 0.509927,-0.338935,0.271009,-0.232425,0.206431 /$

DATA GNU/2.4048,5.5201,8.6537,11.7315,14.9309/

DATA NAME/10HHANS RODER, $10 \mathrm{H} \times 3528,10 \mathrm{H}$

$110 \mathrm{H}$

$210 \mathrm{H}$

$, 10 \mathrm{H}, 10 \mathrm{H}$

, $10 \mathrm{H}$

i

C PT, HELIUM, 0.0005 INCH WIRE

C INITIALIZE

IF $L=156$

CALL $\operatorname{GRPH}(0,0,8$, NAME $, 0,0)$

$\mathrm{RI}=100.1299$

$\mathrm{R} 2=100.1428$

RHOPT $=21.37$

$A=0.000635$

$\mathrm{B}=0.45$

$\mathrm{PI}=3.14159$

DENT $=20$.

PRINT 1

1 FORMAT(1H1/* RUNPT PRT-T WIRE-T R3Z R4Z TINC 1VOLTS PRESS DEN

2 POWER*/) T-EXP TC-EXP STAT TC-TN

C READ DATATC

DO $200 \mathrm{~K}=1,78$

TTRIAL $=1.0$

$\operatorname{READ}(1$, *) IDATE , IRUNPT , PRT , PRT1 , COUNTS , BAR

100 CONTINUE

$\operatorname{IF}(E O F(1)) 9999,100$

$\operatorname{READ}(1, *) \mathrm{R} 3 \mathrm{Z}, \mathrm{R} 3 \mathrm{~B}, \mathrm{R} 4 \mathrm{Z}, \mathrm{R} 4 \mathrm{~B}, \mathrm{TINC}, \mathrm{VNOVA}$

DO $11 \mathrm{I}=1,50$

$\mathrm{L}=(\mathrm{I}-1) * 5$

$\operatorname{READ}(1, *) \operatorname{VOF}(L+1), \operatorname{VOF}(L+2), \operatorname{VOF}(L+3), \operatorname{VOF}(L+4), \operatorname{VOF}(L+5)$

IF (EOF (1)) 9999,11 
C

C

C

$$
\text { DO } 12 I=1,250
$$

$12 \operatorname{VOF}(I)=\operatorname{VOF}(I)-0.000012$

$30 \mathrm{R}=\mathrm{PRT} / 2000$. PRTT $=$ TEMPP $(R)$

TEMP $=$ PRTT

CPPT $=0.129+0.004 / 80 *($ TEMP -220.$)$

$\mathrm{TCPT}=0.74-0.03 / 100 * *(\mathrm{TEMP}-300$.

DIFPT $=$ TCPT $/$ RHOPT $/$ CPPT

PSIA $=0.8728+1.0351740 *$ COUNTS $-0.183212 \mathrm{E}-6 *$ COUNTS $* * 2$

$\mathrm{R} 3 \mathrm{C}=-0.319308 \mathrm{E}-1+0.637332 \mathrm{E}-3 * \mathrm{TEMP}+0.151192 \mathrm{E}-5 * \mathrm{TEMP} * * 2$

$1-0.262966 \mathrm{E}-8 *$ TEMP**3

$\mathrm{R} 4 \mathrm{C}=-0.806515 \mathrm{E}-1+0.151734 \mathrm{E}-2 * \mathrm{TEMP}+0.582652 \mathrm{E}-5 * \mathrm{TEMP} * * 2$

$1-0.899257 \mathrm{E}-8 * \mathrm{TEMP} * * 3$

$\mathrm{R} 3 \mathrm{Z}=\mathrm{R} 3 \mathrm{Z}-\mathrm{R} 3 \mathrm{C}$

$\mathrm{R} 3 \mathrm{~B}=\mathrm{R} 3 \mathrm{~B}+\mathrm{R} 3 \mathrm{C}$

$\mathrm{R} 4 \mathrm{Z}=\mathrm{R} 4 \mathrm{Z}-\mathrm{R} 4 \mathrm{C}$

$\mathrm{R} 4 \mathrm{~B}=\mathrm{R} 4 \mathrm{~B}+\mathrm{R} 4 \mathrm{C}+0.0024$

PRESS $=$ PSIA $/ 14.696$

VOLT $2=2 \cdot 0 *$ VNOVA

VEST $=0.5$

DO $4 \mathrm{I}=1,50$

HPVOLT $=$ VEST +0.1

VMIN $=$ HPVOLT $* 0.99$

VMAX $=$ HPVOLT $* 1.01$

IF (VOLT2 .GT . VMIN . AND .VOLT2 .LT .VMAX) GO TO 5

4 VEST $=$ VEST +0.5

5 CONTINUE

$\mathrm{R} 3=\mathrm{R} 3 \mathrm{Z}+\mathrm{R} 3 \mathrm{~B}$

$\mathrm{R} 4=\mathrm{R} 4 \mathrm{Z}+\mathrm{R} 4 \mathrm{~B}$

RBRIDGE $=1.0 /(1.0 /(R 3+R 4)+1.0 /(R 1+R 2))$

RCIR $=100 \cdot 3288+R B R I D G E$

VOLTS $=$ HPVOLT/RCIR*RBRIDGE

C CALCULATE DELTA-T AND T-CORRECTIONS

IST $=51$

IF (IRUNPT . GE . 9070) IST $=15$

ISTOP $=250$

IF (IRUNPT . EQ . 9070) ISTOP $=220$

IF (IRUNPT .EQ.9071) ISTOP $=180$

IF (IRUNPT . EQ . 9072) ISTOP $=155$

IF (IRUNPT .EQ.9073) ISTOP $=126$

IF (IRUNPT .EQ .9074) ISTOP=110

IF (IRUNPT.EQ.9075) ISTOP $=82$

IF (IRUNPT .EQ.9076) ISTOP $=25$

IF (IRUNPT.EQ.9077) ISTOP $=25$

$\mathrm{V} 250=\mathrm{VNOVA} / 1.00319$

$\mathrm{V} 50=\mathrm{V} 250 / 1.00033$

$\mathrm{CV} 2=(\mathrm{V} 250-\mathrm{V} 50) /(\operatorname{ALOG}(\operatorname{TINC} * 250)-\operatorname{ALOG}(\mathrm{TINC} * 50))$

$\mathrm{CV1}=\mathrm{V} 50-\mathrm{CV} 2 *$ ALOG $($ TINC $* 50)$ 
DO $8 \quad I=1,250$

$8 \operatorname{VOLT}(\mathrm{I})=\mathrm{CV} 1+\mathrm{CV} 2 * \operatorname{ALOG}(\mathrm{TINC} * \mathrm{I})$

DTW=(FINDDT (VOLT (IST), VOF (IST), TTRIAL)+FINDDT (VOLT(ISTOP),

1 VOF(ISTOP), TTRIAL)) $/ 2$.

TEM=DTW+TEMP

RESW3 = FIND1 ( TEM)

RESW4=FIND2 (TEM)

RTOTAL $=$ R3B + R4B +RESW $3+$ RESW4

$\mathrm{IQ}=($ IST $+\mathrm{ISTOP}) / 2+1$

$\mathrm{Q}=(\operatorname{VOLT}(\mathrm{IQ}) / \mathrm{RTOTAL}) * * 2 *(\mathrm{RESW} 3+\mathrm{RESW} 4) * 100 . / 15.596$

DEN=FNDDHE (PRESS , TEMP)

RHOGAS $=$ DEN*4 .0026/1000.

TC $=$ THERHE $(D E N$, TEMP $) / 10$.

CPGAS $=$ CPHE $($ DEN, TEMP $) / 4.0026$

CVGAS $=$ CVHE $(D E N$, TEMP $)$

DIFGAS $=\mathrm{TC} / 100 . / \mathrm{RHOGAS} / \mathrm{CPGAS}$

$\mathrm{QQ}=\mathrm{Q} /(4 . * \mathrm{PI} * \mathrm{TC})$

$\mathrm{QQQ}=\mathrm{Q} * 8.3143 * 10 . /\left(\mathrm{DEN} * \mathrm{CPGAS}^{2} 39.948 *\right.$ CVGAS $\left.* \mathrm{PI} * \mathrm{~B} * * 2\right)$

$\mathrm{QQQQ}=8 . * \mathrm{PI} * \mathrm{~A} / 100 . * 5.6697 \mathrm{E}-8 * \mathrm{TEMP} * * 3 / \mathrm{Q}$

TIME $=0$.

DO $3 I=1,250$

TIME $=$ TIME+TINC

TLOG $(I)=A L O G(T I M E * 1000$.)

DELT $=Q Q * A L O G(4.0 * D I F G A S * T I M E / A * * 2 / 1.781)$

$\operatorname{DTR}(I)=F I N D D T(\operatorname{VOLT}(I), \operatorname{VOF}(I), T T R I A L)$

TTRIAL $=\mathrm{DTR}(\mathrm{I})$

DT1 $(\mathrm{I})=A * * 2 *($ RHOPT $*$ CPPT-RHOGAS*CPGAS $) /(2 . * T C / 100 . *$ TIME $) *$ DELT

$1-Q Q * A * * 2 /(4 . *$ DIFGAS*TIME $) *(2 .-D I F G A S / D I F P T)$

$\mathrm{DT} 2(\mathrm{I})=0$.

$B K T=B * * 2 /(D I F G A S * T I M E)$

IF (BKT.GT.5.78) GO TO 10

$\mathrm{BRAK}=0$.

DO $9 \mathrm{~J}=1,5$

$9 \mathrm{BRAK}=\mathrm{BRAK}+\mathrm{EXP}(-\mathrm{GNU}(\mathrm{J}) * * 2 * \mathrm{DIFGAS} * \mathrm{TIME} / \mathrm{B} * * 2) *(\mathrm{PI} * \mathrm{BFY}(\mathrm{J})) * * 2$

$\mathrm{DT} 2(\mathrm{I})=\mathrm{QQ} *(\operatorname{ALOG}(4.0 * \mathrm{DIFGAS} * \mathrm{TIME} / \mathrm{B} * * 2 / 1.781)+\mathrm{BRAK})$

10 CONTINUE

$\mathrm{DT} 3(\mathrm{I})=-\mathrm{QQQ}$ *TIME

$\operatorname{DT} 4(I)=0$.

$\operatorname{DT5}(I)=Q Q Q Q * D E L T * * 2$

$\operatorname{DTC}(I)=\operatorname{DTR}(\mathrm{I})+\mathrm{DT} 1(\mathrm{I})+\mathrm{DT} 2(\mathrm{I})+\mathrm{DT} 3(\mathrm{I})+\mathrm{DT} 4(\mathrm{I})+\mathrm{DT} 5(\mathrm{I})$

$\mathrm{TTT}=\mathrm{TEMP}+\mathrm{DTR}(\mathrm{I})$

$\mathrm{R} 3=\mathrm{FIND} 1(\mathrm{TTT})+\mathrm{R} 3 \mathrm{~B}$

R4=FIND2 (TTT) + R4B

RBRIDGE $=1.0 /(1.0 /(R 3+R 4)+1.0 /(R 1+R 2))$

$\operatorname{VOLT}(I)=$ HPVOLT $*$ RBRIDGE $/($ RBRIDGE +100.3288$)$

RTOTAL $=R 3+R 4$

RESW3=R3-R3B

RESW4 $=$ R4 - R $4 B$

$\mathrm{QI}(\mathrm{I})=(\operatorname{VOLT}(\mathrm{I}) / \mathrm{RTOTAL}) * * 2 *(\mathrm{RESW} 3+\mathrm{RESW} 4) * 100 . / 15.596$

3 CONTINUE

DO $54 \mathrm{I}=1,250$

$54 \operatorname{DTC}(\mathrm{I})=\mathrm{DTC}(\mathrm{I}) * \mathrm{QI}(\mathrm{IQ}) / \mathrm{QI}(\mathrm{I})$

C LEAST SQUARE DELTA-T VS. LOG(TIMES) 
C

CALL LS

DO $7 \mathrm{I}=1,2$

$7 \mathrm{G}(\mathrm{I})=0.0$

NFUN $=2$

$\mathrm{NF}=2$

NO PTS=ISTOP-IST+1

DO 17 L=IST, ISTOP

$F(1)=1.0$

$F(2)=T L O G(L)$

$16 \mathrm{Y}=\mathrm{DTC}(\mathrm{L})$

17 CALL FIT

CALL COEFF

DO $20 \mathrm{I}=1, \mathrm{NF}$

$20 \mathrm{G}(\mathrm{I})=\mathrm{F}(\mathrm{I})$

DO $13 \quad I=1,250$

$\operatorname{DTR}(I)=(\operatorname{DTC}(I)-(G(1)+G(2) * \operatorname{TLOG}(I))) / \operatorname{DTC}(I) * 100$.

13 CONTINUE

CALL PLOT1(IRUNPT)

CALL STAT

$\operatorname{TCSTAT}=F(2) / G(2)$

C CALCJLATE THERMAL CONDUCTIVITY

DEN $=$ FNDDHE $($ PRESS, TEM $)$

$\mathrm{DENT}=\mathrm{DEN}$

TC=THERHE $($ DEN, TEM $) / 10$.

TCEXP $=Q /(4 . * 3.14159 * G(2))$

PCT $=($ TCEXP-TC $) / T C E X P * 100$.

PRINT 50, IRUNPT, PRTT , TEMP, R3Z, R4Z, TINC, VOLTS , PRESS, DEN,

1 TEM, TCEXP, TCSTAT, TC, PCT, Q

50 FORMAT(I6,2F9.3 ,2F9 .4 , F9 .5, F7 .2 ,F9 .3, F8 .4 , F9 .3 , F9 .5 , F8 .3,

1 F9.5, F8.2, F9.5)

C PLOT RESULTS

200 CONTINUE

CALL PLOT(G(1),G(2), IRUNPT)

9999 CONTINUE

CALL ENDGRPH $(0,0,0,0,0,0)$

CALL DDDF

END

FUNCTION OFFSV(EB,RR1, RR2)

C CALCULATES OFFSET VOLTAGE WHEN RESISTANCES ARE KNOWN

COMMON/DATATC/R1, R2 , R3Z , R4Z, R3B , R4B , PRESS , TEMP, VOF , TINC

DATA(RG $=1.0 \mathrm{E}+07)$

$R 3=R R 1+R 3 B$

$R 4=R R 2+R 4 B$

$\mathrm{DIV}=\mathrm{R} 1 * \mathrm{R} 2 * \mathrm{R} 3+\mathrm{R} 2 * \mathrm{R} 3 * \mathrm{R} 4+\mathrm{R} 3 *_{\mathrm{R}} 4 * \mathrm{R} 1+\mathrm{R} 4 *_{\mathrm{R}} 1 * \mathrm{R} 2+\mathrm{RG} *(\mathrm{R} 1+\mathrm{R} 2) *(\mathrm{R} 3+\mathrm{R} 4)$

GALVI $=E B *(R 2 * R 3-R 1 * R 4) / D I V$

OFFSV $=$ GALVI $*$ RG

RETURN

END

FUNCTION FINDI(TIN)

C WIRE RESISTANCE AS A FUNCTION OF TEMPERATURE 
COMMON/DATATC/R1, R2, R3Z , R4Z ,R3B , R4B , PRESS, TEMP , VOF , TINC

$\mathrm{P}=$ PRESS $* 14.696$

IF(TIN.GT.150.) GO TO 2

FINDI $=-10.231206+0.3670809 * T I N-0.9903371 \mathrm{E}-4 * \mathrm{TIN} * * 2-0.5375358 \mathrm{E}-5 * \mathrm{P}$ RETURN

2 FINDI $=-9.0654718+0.35344447 * \mathrm{TIN}-0.59234427 \mathrm{E}-4 *^{*} \mathrm{TIN}^{*} * 2-0.966271 \mathrm{E}-5 * \mathrm{P}$ RETURN

END

FUNCTION FIND2(TIN)

C

WIRE RESISTANCE AS A FUNCTION OF TEMPERATURE

COMMON/DATATC/R1, R2, R3Z, R4Z, R3B , R4B , PRESS , TEMP , VOF , TINC

$\mathrm{P}=\mathrm{PRESS} * 14.696$

IF(TIN.GT.150.) GO TO 2

FIND2 $=-5.057558+0.1823527 * \mathrm{TIN}-0.525728 \mathrm{E}-4 * \mathrm{TIN} * * 2-0.285743 \mathrm{E}-5 * \mathrm{P}$

RETURN

2 FIND2 $=-4.346459+0.17402506 *$ TIN $-0.2831553 \mathrm{E}-4 * \mathrm{TIN} * * 2-0.452695 \mathrm{E}-5 * \mathrm{P}$ RETURN

END

FUNCTION FINDDT(V1,V2,T1)

C

AN APPROXIMATION, TO REPLACE WIRE-R

COMMON/DATATC/R1, R2, R3Z, R4Z , R3B , R4B , PRESS , TEMP , VOF , TINC

$\mathrm{V}=\mathrm{V} 2$

$\mathrm{TT}=\mathrm{T} 1+\mathrm{TEMP}$

DO $10 \mathrm{I}=1,10$

RE1=FIND1 (TT)

RE2=FIND2 (TT)

VOFF1 $1=0 F F S(V 1, R E 1, R E 2)$

$\operatorname{IF}(A B S(V-V O F F 1)-1.0 E-6 ） 20,20,1$

$1 \mathrm{~T}=\mathrm{TT}+0.01$

RE1 $=F I N D 1(T)$

RE2=FIND2 ( $T$ )

VOFF2 =OFFSV(V1,RE1,RE2)

DVDT $=($ VOFF2-VOFF1 $) / 0.01$

CORR $=(V-V O F F 1) / D V D T$

$10 \mathrm{TT}=\mathrm{TT}+\mathrm{CORR}$

20 FINDDT $=$ TT - TEMP

RETURN

END

FUNCTION TEMPP(R)

C

ABBR. FOR 1776265 FROM 70 TO $310 \mathrm{~K}$, CORR.12/19/80

DIMENSION RR(241)

$\operatorname{DATA}(R R(I), I=1,131) / 3.99645,4.10575,4.21531,4.32508,4.43505$,

$14.54520,4.65550,4.76594,4.87649,4.98714,5.09788,5.20868$,

$25.31954,5.43045,5.54139,5.65235,5.76332,5.87430,5.98527$,

36.09622 , $6.20716,6.31807,6.42895,6.53979,6.65058$,

$46.76134,6.87204,6.98268,7.09327,7.20379$,

$5 \quad 7.31426,7.42465,7.53498,7.64523,7.75541$,

A $7.86552,7.97555,8.08550,8.19538,8.30517,8.41489,8.52453$,

B $8.63408,8.74356,8.85295,8.96226,9.07149,9.18065,9.28971$,

C $9.39870,9.50761,9.61644,9.72519,9.83386,9.94245,10.05096$,

D $10.15939,10.26775,10.37603,10.48424,10.59231,10.70043,10.80841$,

E $10.91632,11.02416,11.13192,11.23962,11.34725,11.45480,11.56229$,

F 11.66971,11.77707,11.88435,11.99158,12.09873,12.20583,12.31286,

G $12.41982,12.52673,12.63357,12.74036,12.84708,12.95375,13.06036$, 
H $13.16690,13.27340,13.37983,13.48621,13.59254,13.69881,13.80502$,

I 13.91118,14.01729,14.12335,14.22935,14.33530,14.44121,14.54706,

J $14.65286,14.75861,14.86431,14.96997,15.07557,15.18113,15.28664$,

K 15.39210,15.49752,15.60289,15.70822,15.81350,15.91873,16.02392,

L $16.12907,16.23417,16.33923,16.44424,16.54922,16.65414,16.75903$,

M 16.86387,16.96868,17.07344,17.17816,17.28284,17.38747,17.49207,

N 17.59663,17.70114,17.80562,17.91006,18.01445/

$\operatorname{DATA}(\mathrm{RR}(\mathrm{I}), \mathrm{I}=132,241) / \quad 18.11881,18.22313,18.32741,18.43165$,

A $18.53586,18.64002,18.74415,18.84824,18.95229,19.05630,19.16028$,

B $19.26422,19.36812,19.47199,19.57582,19.67961,19.78337,19.88709$,

C $19.99078,20.09442,20.19804,20.30162,20.40516,20.50867,20.61214$,

D $20.71558,20.81898,20.92235,21.02568,21.12898,21.23225,21.33548$,

E 21.43867,21.54184,21.64497,21.74806,21.85112,21.95415,22.05715,

F 22.16011,22.26304,22.36594,22.46880,22.57163,22.67443,22.77720,

G 22.87993,22.98263,23.08530,23.18793,23.29054,23.39311,23.49565,

H $23.59816,23.70063,23.80308,23.90549,24.00787,24.11022,24.21254$,

I $24.31483,24.41708,24.51931,24.62150,24.72366,24.82579,24.92789$,

J 25.02996,25.13199,25.23400,25.33597,25.43791,25.53982,25.64170,

K 25.74355,25.84537,25.94715,26.04891,26.15063,26.25232,26.35398,

L $26.45561,26.55721,26.65877,26.76031,26.86181,26.96329,27.06473$,

M 27.16614 ,27.26752,27.36887,27.47019,27.57147,27.67273,

$127.77395,27.87514,27.97631,28.07744,28.17854,28.27961,28.38065$,

$228.48165,28.58263,28.68357,28.78449,28.88537,28.98622,29.08704$,

$329.18783,29.28859 /$

DO $3 \mathrm{I}=1,241$

IF(R.LT.RR(I)) GO TO 4

3 CONTINUE

4 TEMPP $=\mathrm{I}$

TEMPP $=$ TEMPP $+68 .+(R-R R(I-1)) /(R R(I)-R R(I-1))$

RETURN

END

SUBROUTINE LS

LEAST SQUARE ALONG THE DATA

DIMENSION DTR(250), DTC(250), TLOG(250), VOF(250)

DIMENSION $F(40), G(10)$

DIMENSION RES(20), ERR(20), IM(20), $\operatorname{TM}(20)$

COMMON/LSS/DTR, DTC, TLOG, Q, PRTT

COMMON /FITT/ F, Y,NFUN

IST $=11$

DO $13 \mathrm{~J}=1,16$

ISTOP $=$ IST +89

$I M(J)=(I S T+I S T O P) / 2$

$\operatorname{TM}(J)=\operatorname{PRTT}+D T C(\operatorname{IM}(J))$

NFUN $=2$

$\mathrm{NF}=2$

NO PTS=ISTOP-IST+1

DO $17 \mathrm{~L}=$ IST, ISTOP

$F(1)=1.0$

$\mathrm{F}(2)=\mathrm{TLOG}(\mathrm{L})$

$16 \mathrm{Y}=\mathrm{DTC}(\mathrm{L})$

17 CALL FIT 
CALL COEFF

$\operatorname{RES}(J)=Q /(4 . * 3.14159 * F(2))$

CALL STAT

$\operatorname{ERR}(\mathrm{J})=\operatorname{RES}(\mathrm{J}) /(\mathrm{Q} /(4 . * 3.14159 * \mathrm{~F}(2)))$

13 IST $=$ IST +10

PRINT 15,(( IM(J),TM(J)), J=1, 10)

PRINT 14,((RES $(J), \operatorname{ERR}(J)), J=1,10)$

PRINT 15,(( IM(J),TM(J)), J=11,16)

PRINT 14,((RES(J),ERR(J)),J $=11,16)$

14 FORMAT (5X, 20F6.4)

15 FORMAT $(5 X, 10(I 4, F 8.3))$

RETURN

END

SUBROUTINE PLOT(G1, G2, IDNO)

C PLOTS RESULTS

DIMENSION ITITLE (13), NAME (8), ICOMM(2)

DIMENSION DTR(250), DTC(250), TLOG(250), VOF(250)

COMMON/LSS/DTR, DTC, TLOG , Q,PRTT

DATA ITITLE/1OH

110HDUCTIVITY , 10H

210H MILLISEC, $10 \mathrm{H}$

310HT IN $\mathrm{K}, 10 \mathrm{H}$

DATA ICOMM(1)/10H RUNPT /

$\operatorname{ENCODE}(10,1, \operatorname{ICOMM}(2))$ IDNO

1 FORMAT (I10)

NO PTS $=240$

DO $51 \mathrm{I}=11,250$

$\mathrm{L}=\mathrm{I}-10$

TLOG $(\mathrm{L})=$ TLOG $(\mathrm{I})$

$51 \operatorname{DTC}(\mathrm{L})=\operatorname{DTC}(\mathrm{I})$

CALL PGRPH(TLOG,DTC, NO PTS, ITITLE , 0,6)

$\operatorname{DTC}(1)=G 1+G 2 * T L O G(1)$

$\operatorname{DTC}(2)=G 1+G 2 * T L O G(N O$ PTS)

TLOG (2) $=$ TLOG (NO PTS)

CALL CLGRPH(TLOG,DTC, $2,0,0,0$ )

ABFRACT $=0.05$

ORDFR $=0.9$

CALL COMGRPH(ABFRACT, ORDFR, 2, ICOMM)

RETURN

END

SUBROUTINE PLOTI(IDNO)

C PLOTS DEV. FROM LS LINES

$10 \mathrm{H}$ HELIUM T, 10HHERMAL CON, $, 10 \mathrm{H} \quad, 10 \mathrm{HLN}(\mathrm{T}) \mathrm{T}$ IN, ,10H ,10HDELTA T, , i

DIMENS ION ITITLE(13), NAME (8), TT(250), ICOMM(2)

DIMENSION DTR(250),DTC (250), TLOG (250), VOF (250)

COMMON/LSS/DTR, DTC, TLOG, Q,PRTT

DATA ITITLE/10H

110HDUCTIVITY ,10H

210HN MILLISEC, $10 \mathrm{H}$

310HLS FIT , $10 \mathrm{H}$

DATA ICOMM(1)/10H

RUNPT /

, $10 \mathrm{H}$ HELIUM T,10HHERMAL CON,

$\operatorname{ENCODE}(10,1, \operatorname{ICOMM}(2))$ IDNO

1 FORMAT(I10)

NO PTS $=240$

DO $51 \quad I=11,250$ 
$\mathrm{L}=\mathrm{I}-10$

$\operatorname{TT}(\mathrm{L})=\mathrm{TLOG}(\mathrm{I})$

$51 \operatorname{DTR}(\mathrm{L})=\mathrm{DTR}(\mathrm{I})$

CALL PGRPH(TT,DTR, NO PTS, ITITLE, 0,6)

ABFRACT $=0.05$

ORDFR $=0.9$

CALL COMGRPH (ABFRACT, ORDFR, 2, ICOMM)

RETURN

END

SUBROUTINE FITTER

C CHANGED 13 SEPT., 1973 OLDER VERSION OF FITTER

C COMMON STATEMENT ADDED TO MATCH CALLING SEQUENCE OF NEWER VERSION

C SPECIAL, TO GET RESS IN F(10)

DIMENSION $\mathrm{F}(40), \mathrm{A}(40,41)$

COMMON /FITT/ F,Y,NFUN

DOUBLE PRECISION A,SY,SYY,RES, DET

EQUIVALENCE (NC, FNC)

DATA (NTR=-1)

$\$ \operatorname{DATA}(\mathrm{NDIM}=40)$

ENTRY FIT

IF(NTR) $1,3,3$

$1 \mathrm{NP}=0$

$\mathrm{NF}=\mathrm{NFUN}$

IF(NF.GT.NDIM) GO TO 44

$\mathrm{NC}=0$

$S Y=0$.

$S Y Y=0$.

$\mathrm{NY}=\mathrm{NF}+1$

DO $2 \mathrm{I}=1$, NY

DO $2 \mathrm{~J}=1, \mathrm{NF}$

$2 A(J, I)=0$.

IF(NTR.EQ.0) GO TO 11

NTR $=0$

$3 \mathrm{SY}=\mathrm{SY}+\mathrm{Y}$

$S Y Y=S Y Y+Y * Y$

DO $4 \mathrm{~J}=1, \mathrm{NF}$

$\mathrm{A}(\mathrm{J}, \mathrm{NY})=\mathrm{A}(\mathrm{J}, \mathrm{NY})+\mathrm{Y} * \mathrm{~F}(\mathrm{~J})$

DO $4 \mathrm{I}=1, \mathrm{NF}$

$4 \mathrm{~A}(\mathrm{I}, \mathrm{J})=\mathrm{A}(\mathrm{I}, \mathrm{J})+\mathrm{F}(\mathrm{I}) * \mathrm{~F}(\mathrm{~J})$

$\mathrm{NP}=\mathrm{NP}+1$

RETURN

ENTRY CONSTR

IF(NTR) $10,11,11$

10 NTR $=0$

GO TO 1

II $\mathrm{N}=\mathrm{NY}-1$

IF (NY+NC+2.GT.NDIM) GO TO 44

DO $12 \quad I=1, N$

$\mathrm{A}(\mathrm{I}, \mathrm{NY}+1)=\mathrm{A}(\mathrm{I}, \mathrm{NY})$

$12 \mathrm{~A}(\mathrm{I}, \mathrm{NY})=\mathrm{A}(\mathrm{NY}, \mathrm{I})=\mathrm{A}(\mathrm{NDIM}-\mathrm{NC}, \mathrm{I})=\mathrm{F}(\mathrm{I})$

$\mathrm{NC}=\mathrm{NC}+1$

DO $13 \mathrm{I}=\mathrm{NF}, \mathrm{N}$

$13 \mathrm{~A}(\mathrm{I}+1, \mathrm{NY})=\mathrm{A}(\mathrm{NY}, \mathrm{I}+1)=0$.

$\mathrm{NY}=\mathrm{NY}+1$

$A(N Y-1, N Y)=Y$ 


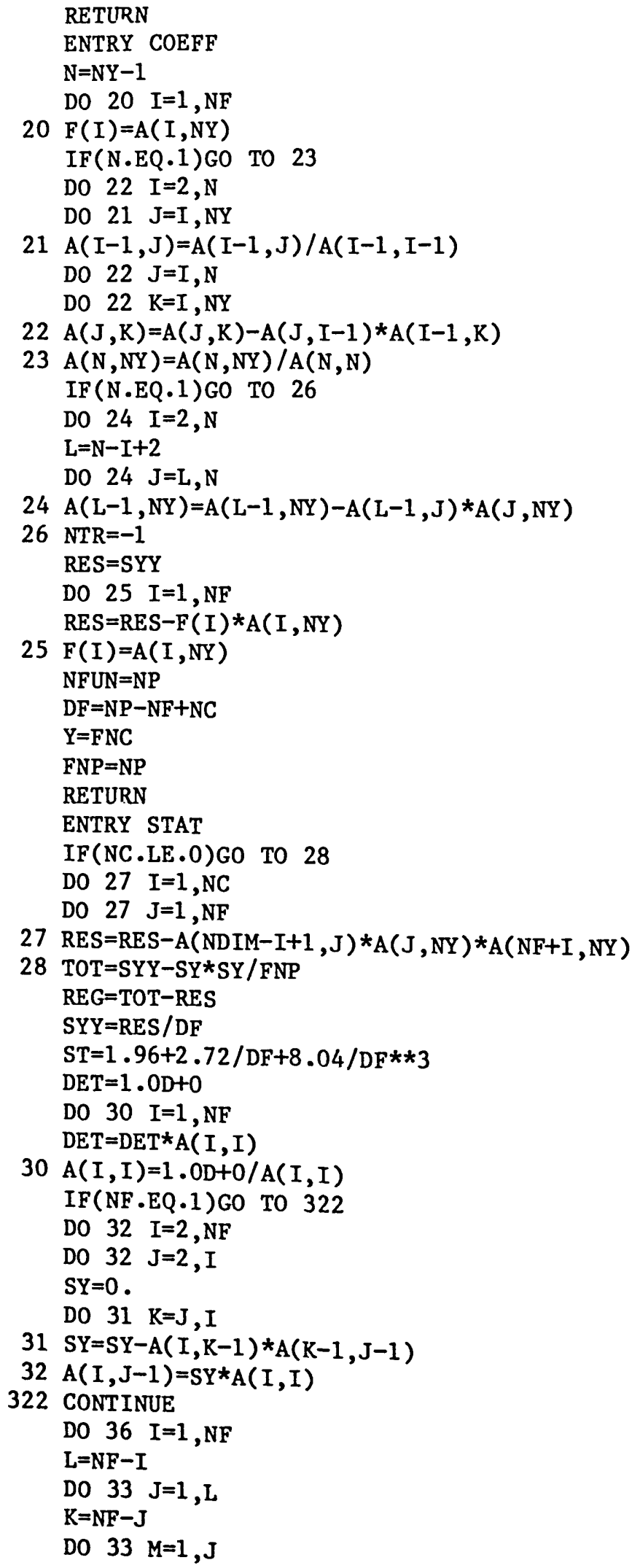


$\mathrm{N}=\mathrm{NF}-\mathrm{M}+1$

$33 A(K, I)=A(K, I)-A(K, N) * A(N, I)$

IF(I.EQ.1)GO TO 344

DO $34 \mathrm{~J}=2, \mathrm{I}$

$34 \mathrm{~A}(\mathrm{~J}-1, \mathrm{I})=\mathrm{A}(\mathrm{I}, \mathrm{J}-1) * \mathrm{SYY}$

344 CONTINUE

DO $35 \mathrm{~J}=1, \mathrm{I}$

$35 \mathrm{~A}(\mathrm{I}, \mathrm{J})=\mathrm{A}(\mathrm{I}, \mathrm{J}) * \mathrm{SYY}$

$\operatorname{IF}(A(I, I) \cdot L E \cdot 0.0) A(I, I)=-A(I, I)$

$36 \mathrm{~F}(\mathrm{I})=\mathrm{ST} * \mathrm{DSQRT}(\mathrm{A}(\mathrm{I}, \mathrm{I}))$

C

PRINT $37,(A(I, N Y), F(I), I=1, N F)$

37 FORMAT(*1THE COEFFICIENTS AND THEIR ESTIMATED ERRORS ARE:*/

$1(* * \mathrm{E} 18 \cdot 10, *$ +OR-*E9.2))

$S Y Y=D S Q R T(S Y Y)$

C PRINT 38, RES, REG,TOT,SYY,DET

$F(10)=R E S$

38 FORMAT(

* ESTIMATED RESIDUAL SUM OF SQUARES $=*$ E17.9/

1

* ESTIMATED REGRESSION SUM OF SQUARES $=*$ E17.9/

2

* ESTIMATED TOTAL SUM OF SQUARES $=*$ E17.9/

3* STANDARD DEVIATION $=*$ E17.9/* DETERMINANT OF THE MATRIX $=*$ E $17.9 /$

4 * DISPERSION MATRIX* )

DO $39 \mathrm{~J}=1, \mathrm{NF}$

C 39 PRINT $40,(\mathrm{~A}(\mathrm{I}, \mathrm{J}), \mathrm{I}=1, \mathrm{NF})$

39 CONTINUE

40 FORMAT (7E19.9)

C PRINT 46

46 FORMAT (1H )

RESSS $=$ RES

$\mathrm{Y}=\mathrm{SQRT}$ (RESSS/DF)

$\mathrm{NFUN}=\mathrm{DF}$

43 RETURN

44 PRINT 45

45 FORMAT(*1THE ARRAYS IN THE FITTING PROGRAM ARE TOO SMALL TO HOLD T IHE NUMBER OF CONSTRAINTS AND FUNCTIONS ASKED FOR IN THE CALLING PR 2OGRAM*)

STOP

END 